\title{
RETÓRICA Y CONTABILIDAD: DE LA CRÍTICA RETÓRICA A LA RETÓRICA CRÍTICA*
}

\author{
GUSTAVO ALBERTO RUIZ ROJAS** \\ UNIVERSIDAD AUTÓNOMA LATINOAMERICANA
}

Recibido/ Received/ Recebido: 27/01/2016-Aceptado/ Accepted / Aprovado: 03/07/2016

\begin{abstract}
Resumen
Los estudios críticos del discurso contable, reiteran que la retórica es un instrumento al servicio de la dominación y desconocen los potenciales emancipadores que subyacen en su ejercicio deliberativo. Esto porque la consideran un dominio exclusivo de los grupos hegemónicos, y reducen el concepto a su aspecto discursivo, eliminando sus implicaciones éticas. Este artículo hace una revisión del tema, apelando a una metodología de tipo cualitativo, a partir de artículos de investigación publicados en revistas de contabilidad anglosajonas, que aparecen registradas en la base de datos Scopus. Se identifican algunas experiencias que reconocen en la retórica, un dominio necesario para emprender deliberaciones públicas desde lo contable. Se concluye que una retórica al servicio de la transformación de los lugares comunes y guiada por lo preferible, puede contribuir a la deliberación pública.

Palabras clave: Retórica; Discurso; Contabilidad; Deliberación; Crítica retórica.
\end{abstract}

\section{RHETORIC AND ACCOUNTING: FROM RHETORICAL CRITICISM TO CRITICAL RHETORIC}

\begin{abstract}
Critical studies of accounting speech, reiterate that rhetoric is an instrument of domination and doesn't recognize the emancipatory potential underlying its deliberative exercise. This is because they consider it an exclusive domain of hegemonic groups and reduce the concept to its discursive aspect, eliminating its ethical implications. This article reviews the issue, appealing to a qualitative methodology, from research articles published in Anglo-Saxon accounting journals which are listed in the Scopus database. Some experiences that recognize in rhetoric a necessary domain to undertake public deliberations from the accounting matter are identified. It is concluded that rhetoric at the service of the transformation of commonplaces and preferably guided can contribute to public deliberation.
\end{abstract}

Keywords: Rhetoric; Speech; Accounting; Deliberation; Rhetorical criticism.

Artículo de reflexión derivado del proyecto: "Vínculos entre la retórica deliberativa y el sentido de lo público en el contador" (Código 17-000012), perteneciente a la Universidad Autónoma Latinoamericana.

Licenciado en español y literatura (Universidad de Antioquia), magíster en educación (Universidad San Buenaventura, Medellín), profesor de tiempo completo de la Facultad de Contaduría Pública de la Universidad Autónoma Latinoamericana, Medellín. Docente investigador perteneciente al Grupo GICOR. Dirección postal: Carrera 55A N 49-51, Medellín (Colombia). Teléfono: (57-4) 31054965 42. Correo electrónico: gustavo.ruiz@unaula.edu.co 


\title{
RETÓRICA E CONTABILIDADE: DA CRÍTICA RETÓRICA À RETÓRICA CRÍTICA
}

\begin{abstract}
Resumo
Os estudos críticos do discurso contábil, reiteram que a retórica é um instrumento a serviço da dominação e desconhecem os potenciais emancipadores que subjazem em seu exercício deliberativo. Isto porque a consideram um domínio exclusivo dos grupos hegemónicos, e reduzem o conceito a seu aspecto discursivo, eliminando suas implicações éticas. Este artigo faz uma revisão do tema, utilizando uma metodologia de tipo qualitativo, a partir de artigos de pesquisa publicados em revistas de contabilidade anglo-saxãs, que aparecem registradas no banco de dados Scopus. Identificam-se algumas experiências que reconhecem na retórica um domínio necessário para empreender deliberações públicas desde o contábil. Conclui-se que uma retórica a serviço da transformação dos lugares comuns e guiada pelo preferível, pode contribuir à deliberação pública. Palavras chave: Retórica; Discurso; Contabilidade; Deliberação; Crítica retórica.
\end{abstract}

Ruiz, G. (2017). Retórica y contabilidad: de la crítica retórica a la retórica crítica. En: Revista de la Facultad de Ciencias Económica: Investigación y Reflexión. rev.fac.cienc.econ, XXV(1). DOI: http://dx.doi.org/10.18359/rfce.2660

JEL: $M 41,219$.

\section{Introducción}

El trabajo de Quinche (2011) en torno a los vínculos entre la retórica y la contabilidad, es pionero en Colombia. Inicialmente contextualiza los estudios retóricos como parte de las investigaciones interpretativas; posteriormente construye una conceptualización contemporánea de la retórica a partir de diversos autores que la reducen a un discurso instrumental orientado a modificar opiniones, reforzar las ya existentes o a responder a las opiniones de un público determinado (Gill \& Whedbee, 2000, citado por Quinche, 2011). Esta definición permite situar la crítica retórica como un campo de investigación cuyo propósito es efectuar el análisis de los discursos con el fin de entender de qué manera actúan con el fin de modificar, reforzar o responder a esas opiniones.

Con base en Latour \& Wolgar (1995), Potter (1998) y Bazerman (2005) citados por Quinche (2011), se amplía el concepto hacia el campo de la ciencia, en tanto la retórica está en el centro de las discusiones científicas de diversa índole; tanto por su carácter argumentativo, como por el aspecto persuasivo inherente a todo discurso científico, a pesar de su aparente neutralidad. Vista así, la persuasión sigue siendo un acto estratégico a pesar de que Bazerman (1998, citado por Quinche, 2011) reconoce en ella una forma profunda e irresistible de arrasar con los argumentos más superficiales.

Con base en el marco metodológico de la retórica aristotélica, propone los cruces entre contabilidad y retórica. En cuanto a los géneros retóricos, propone un vínculo entre los géneros y su aplicación en la contabilidad. Así lo deliberativo se evidencia en los informes contables que se usan para analizar las acciones futuras; en lo judicial se refiere a todos los informes que dan cuenta de la bondad o no de ciertas acciones tomadas y en lo epidíctico, en la valoración que las organizaciones hacen de sí mis- 
mas en sus propios informes, intentando con ello proyectar una imagen positiva.

Los momentos de la construcción del discurso los explica con base en el proceso inherentemente selectivo de la representación contable, su forma de organización (expresado en ciertas técnicas) y su forma de representación con el fin de hacer pública esta información. Esto conduce a la aplicación de argumentos contables que se asimilan a los tipos de argumentos mediante el logos, el ethos y el pathos

Alude al carácter metafórico de los conceptos contables, y en lo relacionado con las audiencias remite a los usuarios de la información, tema ampliamente debatido; en tanto que las ausencias las relaciona con la información netamente monetaria que deja de lado otras formas de representación. A modo de conclusión, deriva los potenciales investigativos del cruce contabilidad, retórica: la retórica de la ciencia y de la investigación en contabilidad, retórica y regulación contable, retórica de las teorías contables, retórica en la educación contable, la retórica en las prácticas contables y la contabilidad como herramienta retórica. Todos propuestos a partir de diversas investigaciones que se han publicado en las principales revistas de contabilidad anglosajonas (Accounting, Auditting and Accountability Journal; Critical Perspectives on Accounting; Accounting, Auditing and Accountability Journal; Accounting Forum, entre otras).

En Quinche (2012) se enmarcan las corrientes de la investigación contable con base en el referente de los Estudios Sociales de la Ciencia y la Tecnología (ESCT). Quinche (2014) toma como punto de partida toda la construcción anterior, para derivar a partir de allí un ejercicio de análisis crítico enmarcado en la línea de la retórica en las prácticas contables que había propuesto en el primer artículo (Quinche, 2011). En este trabajo emprende un análisis retórico de las cartas de los presidentes incluidos en los informes de sostenibilidad publicados por tres empresas en Colombia correspondientes al año 2009. Concluye que estas pertenenecen al género epidíctico por apuntar al encomio con el fin de mostrarse como sostenibles y responsables socialmente; de allí deriva las estrategias argumentativas desde el ethos, caracterizadas por el uso del "nosotros", como estrategia para provocar vaguedad y disipar las responsabilidades de quienes toman decisiones y por la visualización como empresas responsables por su tendencia al éxito; al pathos por su alusión a la crisis del país, su apelación a valores compartidos y su compromiso con el progreso, el crecimiento y el éxito obtenido que las muestra como ejemplo a seguir para superar las crisis. Todo esto reforzado con los argumentos desde el logos el cual mediante cifras muestra el éxito económico (Quinche, 2014).

Sostiene que esta clase de investigación busca abrir discusiones críticas sustentadas en marcos teóricos y metodologías provenientes de diversos campos de las ciencias sociales y que alimentan la evaluación del papel de la contabilidad en nuestra sociedad, más allá de considerarla como un mero reflejo de la realidad objetiva (Quinche, 2014). Además rescata la retórica, lo cual permitirá a los investigadores contables reconocer aproximaciones conceptuales y metodológicas que nutran sus esfuerzos investigativos en la vertiente crítica de la contabilidad. Sin embargo, en toda su construcción se destacan dos "ausencias" fundamentales que distorsionan, una vez más, el sentido de la retórica. La primera omite el concepto clásico de retórica, a pesar de que toma elementos de su arsenal metodológico; esto reduce el concepto a su aspecto discursivo, dejando de lado los vínculos con la filosofía y con las pasiones, fundamentales en la concepción de lo preferible. La segunda reduce el valor de la retórica al análisis críti$\mathrm{co}$, en detrimento de su potencial como ejercicio de discusión crítica, lo que permitiría comprender que la retórica no es solo un instrumento al servicio del pensamiento hegemónico, sino que posee un vínculo sustancial con las aspiraciones emancipatorias de una sociedad equitativa y democrática.

Teniendo en cuenta la escasa presencia de esta temática en el ámbito nacional, y la tradición en el campo de la crítica retórica en el contexto anglosajón, en este artículo emprendo una revisión bibliográfica que permite, en primer lugar, rastrear las presencias y omisiones que pueden existir detrás de los artículos de investigación retórica que se han desarrollado en el contexto de las revistas de investigación de tradición anglosajona, $y$, en segundo 
lugar, destacar los pocos artículos en los cuales se propone la retórica como un recurso que no es exclusivo de las fuerzas hegemónicas, sino que puede ser utilizado con fines emancipatorios.

El artículo se organiza de la siguiente forma: en primer lugar se describen los aspectos metodológicos esenciales. Posteriormente se efectúa una síntesis de los principales hallazgos que se encuentran al analizar la manera como se nombra la retórica en los resúmenes de los artículos que acuden a la crítica retórica. Se evidenciarán las presencias, pero también las ausencias que dichas atribuciones connotan. Posteriormente se hace una caracterización de algunos elementos propios de la retórica clásica, los cuales no se evidencian en las posturas citadas en la tradición de la crítica retórica, así como aquellos que aún sin mencionarse tienen una relación estrecha. Por último, se esbozan las ideas sustanciales de algunos artículos en los cuales la retórica aparece como un discurso político al servicio de la deliberación social. Ello con el fin de sustentar la reivindicación de la retórica como un discurso deliberativo al servicio de las luchas sociales, y no solo como un método de análisis del discurso, en el mejor de los casos, o de manipulación y engaño, en el peor.

\section{Metodología}

La investigación es cualitativa de tipo hermenéutico. Se orienta mediante el análisis de contenido de fuentes documentales. Para este caso las fuentes documentales se toman de los artículos de investigación publicados en las revistas de contabilidad anglosajonas, que aparecen registradas en la base de datos Scopus.

La selección parte de una búsqueda en la cual se incluyen dos términos: acccounting and rhetoric, la cual arrojó un total de 115 artículos. No es del interés de este trabajo hacer una descripción cuantitativa de la distribución de artículos por revista. Baste anotar que con base en la lista se genera una base de datos en Excel y se procede a una primera lectura superficial de todos los resúmenes. Una vez concluida esta exploración, se separan aquellos que están en la línea de la crítica retórica, y derivan en una connotación negativa del término, de aquellos que abiertamente presentan posibilidades para efectuar una reivindicación de la retórica en relación con lo deliberativo.

Una vez aplicado este primer filtro se procede a leer con mayor detalle, los resúmenes del primer grupo. El foco de interpretación es encontrar algunos patrones en torno a las atribuciones hechas al concepto de retórica. La búsqueda de patrones se refiere a los sentidos, visiones, percepciones, comprensiones sobre un evento o situación que se analiza, en una expresión o en un documento (Ritzer, citado en Galeano, 2004, p. 116). Se busca con ello identificar de qué manera el uso del concepto al interior del enunciado y su relación con lo dicho en el resumen, corresponde a ciertas características de la retórica, pero igualmente, dejan de lado otros aspectos fundamentales de la misma.

La identificación parte del reconocimiento de elementos comunes entre varias afirmaciones, infiriendo su sentido implícito y relacionándolo con algunos conceptos propios de la retórica clásica tanto desde la presencia, como desde aquello que se omite. La discusión de los hallazgos expresará esa lógica, ya que primero se hace una descripción de lo que se encuentra y después se interpreta en relación con la retórica.

Para el otro grupo de artículos se hace una lectura completa, se elabora un resumen de cada uno, para posteriormente redactar un memo analítico en el cual se valora la pertinencia del texto en relación con el propósito argumentativo, que, es menester recalcar, consiste en justificar la retórica como un discurso que puede estar al servicio de la deliberación pública y no solo del acallamiento. Este paso permitió una segunda depuración, ya que algunos artículos no expresaban enfáticamente ese uso deliberativo, a pesar de que algunas conclusiones podrían contribuir a demostrar ese potencial.

\section{Resultados}

\subsection{Sobre crítica retórica}

De acuerdo con Vargas \& Cárdenas (2005), la formación retórica abarca dos ejes: el primero consiste en el ejercicio crítico de deconstruir los discursos 
para develar los supuestos y manipulaciones que se presentan en los discursos públicos. El otro eje es el del ejercicio público del discurso orientado a la deliberación, sobre la base de lo preferible. Dicho ejercicio debe contar necesariamente con el dominio argumentativo y el ejercicio persuasivo propio de la retórica. Ambos deben orientarse bajo el concepto de virtud y prudencia, y en nombre de aquello que se considera bello, bueno y justo.

En esta primera parte se hace una descripción de las investigaciones en la línea de la crítica retórica. Siguiendo a Quinche (2011), el método de la crítica retórica pretende desarmar estructuras textuales para ver cómo operan con el fin de construir consenso.

Si bien Quinche $(2011,2012)$ efectuó algunas agrupaciones de los trabajos que se han desarrollado en este campo, su énfasis estaba más puesto en los temas que abordan los estudios. En tanto, este artículo pretende ubicar algunos conceptos propios de la retórica que se expresan en los mencionados textos. A continuación se describen:

\subsubsection{La retórica como expresión de los topoi}

En el contexto de la interacción social cotidiana, la retórica versa sobre agentes sociales proponiendo su perspectiva acerca de un determinado estado de cosas. Tal y como Hart (1997) y Cyphert (2010) citados por Higgins \& Walker (2012) indican, los actores sociales proponen un punto de vista, permiten el debate y la discusión, y explican sus puntos de vista y posiciones. Estos son todos los medios de forma democrática usados para decidir sobre la constitución del orden social. Por otra parte, algunos actores sociales gozan de una posición privilegiada en la sociedad, y tienen amplios recursos sociales que les permitan ejercer una influencia desproporcionada sobre las percepciones acerca de cómo se forma el orden social. Desde este punto de vista, la contabilidad cumple un papel como fuerza simbólica, cultural y hegemónica en las luchas por la distribución de la renta social (Lehman \& Tinker, 1987). Con este fin, el análisis retórico promueve una visión crítica de información social / ambiental al revelar cómo las estrategias persuasivas ayudan a influir entendimientos sociales en formas que hacen hincapié en los intereses empresariales (Higgins \& Walker, 2012, p. 205).

En este grupo de trabajos, se coincide en esa asimetría, ya que critican la manera como las organizaciones utilizan el poder simbólico de la retórica con el fin de legitimar sus posturas mediante un proceso de alineación a los valores que se consideran aceptables socialmente. Dichos valores confluyen en los topoi o lugares comunes. Aspecto vital en el proceso de elección de los argumentos. Esta revisión permitirá entonces dilucidar algunos de los lugares comunes que la retórica toma para sustentar sus posturas.

La revisión permitió inferir cuatro grupos de lugares comunes. Los primeros en los cuales se hace un uso del valor de lo público y otros valores socialmente aceptados o con potencial crítico, para ir colonizando su sentido desde la lógica del pensamiento único (Gómez, 2007). Los segundos apuntan a esgrimir los valores propios de la racionalidad del capital, como valores positivos que justifican acciones; los terceros se aluden a la reificación de conceptos contables, que limitan las posibilidades representativas de la contabilidad y los últimos aluden al aspecto técnico de la contabilidad y su carácter retórico.

Se cita inicialmente a Baker (2005), quien examina el concepto de interés público en la profesión contable norteamericana, a la luz del concepto de ideología de Ricoeur (1970). Trabajo paradigmático que plantea la coaptación del concepto al ámbito de la empresa. Una traducción de este artículo fue publicada por Mauricio Gómez y Carlos Mario Ospina en el llamado "libro azul" del año 2009. Lo que podría interpretarse como una aplicación de estas ideas, se lleva a cabo en una investigación que examina la manera como en Japón, los conceptos de interés privado e interés púbico han ido cambiando desde 1970. Llega a la conclusión de que los conceptos de interés público y privado, y sus relaciones se han transformado con la ayuda del despliegue retórico de la contabilidad. El concepto de interés privado adquirió forma concreta con la reforma orientada al mercado y avanzó en nombre del interés público (Sawabe, 2005). Así mismo se demuestra como en Australia la retórica del interés público ha generado 
una concentración del $98 \%$ de los fondos privados de pensiones, generando con ello grandes beneficios para los grandes grupos de presión (Taylor, 2011). Otro ejemplo de colonización del discurso gerencialista en los asuntos de interés público, se ejemplifica en un caso de deliberación pública en Dinamarca, donde se concluye que en el debate sobre la salud en ese país el discurso de la Contabilidad de Gestión, se ha ido imponiendo por encima de los asuntos atinentes al juramento hipocrático (Malmmose, 2015).

Estos aspectos conceptuales y sus transformaciones son igualmente abordados en investigaciones que rastrean la manera como el concepto de responsabilidad social se ha pasado de un concepto revolucionario a uno hegemónico, coincidiendo con el paso de unos abordajes polifónicos, a unos más hegemónicos y débiles (Laine, 2010); dicha visión, de corte económico, se impone sobre las interpretaciones del concepto por parte de los diferentes grupos de interés (Mäkelä \& Näsi, 2010).

Otro texto en el cual se describe el uso retórico de ciertas ideas socialmente valoradas, es un artículo histórico en el cual se muestra como el new deal propuesto como un medio para efectuar la restauración moral del capitalismo que propugnaba Dewey, no pasó de ser un tópico que Lewis Douglas aprovechó con el fin de mantener el status Quo, lo cual a juicio de los autores se evidencia en sus estrechos vínculos con la profesión contable y en el hecho de haber sido capturado por ella (Merino \& Mayper, 2001). De igual forma Carmona \& Gutiérrez (2005) se encargan de evidenciar de qué manera el discurso de la compasión se usó en el siglo XVIII en España, como una estrategia para legitimar la subcontratación de Monjas pobres, con el fin de aprovechar la tradición de estas comunidades en el negocio del tabaco, además de obviar los conflictos de género dentro de las fábricas. Es necesario destacar en este punto las investigaciones que recavan en el concepto de Desarrollo Sostenible, como un concepto retórico que presume de armonizar los intereses ambientales, socialmente reclamados, con los intereses económicos (Milne, Tregidga \& Walton, 2009; Laine, 2005; Higgins \& Walker, 2012).
Con respecto a los valores propios de la racionalidad del capital, un primer trabajo analiza cómo la política de financiación privada para servicios públicos en el Reino Unido se fundamenta en la idea de incertidumbre y la gestión del riesgo como conceptos justificadores (Froud, 2003), algo similar se analiza en el caso de la concesión de la construcción de autopistas en Irlanda (Burke \& Demirag, 2015) y la privatización de servicios públicos en Tailandia a partir del discurso de la eficiencia (Sharma \& Lawrence, 2015). De igual manera, se observa como la apelación a la globalización del mercado, el mercado del conocimiento y en general la racionalidad cognitivo económica asociada a la llamada sociedad del conocimiento, opera como un marco conceptual que pretende institucionalizar las expectativas sociales de comportamiento profesional adecuado para legitimar una transformación de las jurisdicciones en relación con los servicios de $\mathrm{Au}$ ditoría Interna (Covaleski, Dirsmith \& Rittenberg, 2003); así como la implementación de las lógicas de la gestión privada sustentadas a partir de la eficiencia y la productividad, lo cual en el ámbito de la educación universitaria pública impactó la formación de los estudiantes (Lawrence \& Sharma, 2002), lo que se expresa en al ámbito profesional en actitudes signadas por la arrogancia y el delirio sobre la base de la exacerbación del ideal de mercado, la libertad, la competitividad y el progreso como actitudes reificantes que facilitaron el caso Enron en momentos previos, y justificaron las actuaciones de los implicados en momentos posteriores al colapso (Craig \& Amernic, 2004).

Desde el punto de vista de la Contabilidad como disciplina, es necesario destacar inicialmente los trabajos que establecen un vínculo entre el surgimiento de la partida doble y el clima cultural de la época. Thompson (1991) atribuye su difusión no solo a la presión de los comerciantes, sino a la influencia de la iglesia, de los editorialistas y de las instituciones pedagógicas, en cuyo seno floreció la retórica como conocimiento escolar; Yamey (2005) encuentra su origen en las actitudes maniqueístas expresadas en la retórica de la época; en tanto el trabajo de Aho (2005) muestra el origen de la partida doble como un intento de conciliar los intereses económicos, concebidos como morales, con el precepto del 
cristianismo. De esta forma el "dar cuenta de", se convierte en expresión del escrúpulo propio de la penitencia, y la partida doble, en la forma de justificar su riqueza.

La investigación de Miller \& O'Leary (1990) concluye que la conceptualización reificante de la contabilidad como disciplina práctica bajo principios de cooperación contractualista hobbesiana y de liderazgo individual, limita los objetivos políticos y morales de la Contabilidad. En sentido similar se encuentran el papel de la contabilidad en la transformación de las empresas norteamericanas de los años 60, las cuales pasaron de una visión productiva a una financiera de la organización (Nelson \& Hirsch, 1990), así como el proceso de cosificación del concepto de valor (Bourguignon, 2005). En la misma línea se plantea como las distorsiones conceptuales que han surgido en inglés en torno al discurso presupuestario, bloquean la posibilidad de desarrollar concepciones alternativas (Ihantola, 2010).

Se destaca en esta línea de reflexión, los trabajos de Lehman (2006) y Angyeman \& Lehman (2013), que investigan cómo la contabilidad convencional oscurece las relaciones sociales complejas, una de las cuales es el uso de mano de obra inmigrante en el logro de los resultados de las empresas, ignorando sus efectos nocivos y haciendo caso omiso de las interdependencias complejas y poderosas fuerzas que entran en juego en el escenario de la migración; aunque también se abre la discusión acerca de nuevas posibilidades de reconocimiento mucho más complejas y críticas (Agyemang \& Lehman, 2013); al igual que el impacto de la globalización económica sobre las mujeres, y el papel que la contabilidad cumple en ello, con lo cual propone una expansión de las posibilidades de la contabilidad para abordar la discusión sobre la perspectiva de género (Lehman, 2012).

En cuanto al uso de la contabilidad como una retórica de corte técnico al servicio de los intereses hegemónicos, Ezzamel, Willmott \& Worthington (2004) demuestran como la incorporación de técnicas contables cada vez más "eficientes" se utilizó para enfrentar la resistencia de los trabajadores frente a la introducción de nuevas técnicas de producción y de control por parte de la gerencia. Por su parte, Craig
\& Armenic $(2006,2008)$ examinan el papel que cumple la contabilidad en los procesos de privatización de los ferrocarriles nacionales en Canadá sosteniendo una profecía autocumplida de éxito (Craig \& Armenic, 2006) o de qué manera la narrativa de la alta dirección en sus cartas a los accionistas, enfatiza en dos puntos de referencia de rendimiento contable (el coeficiente de explotación y el flujo de caja libre) para ayudar a sostener una retórica de éxito después de la privatización de una empresa de transporte en Canadá (Craig \& Armenic, 2008); y como se usan con conceptos contables, tales como los activos y pasivos, para persuadir a las partes interesadas de la viabilidad financiera de una nueva entidad separada, para financiar demandas judiciales de amianto en una empresa de asbesto (Pesci, Costa \& Soobaroyen, 2015). Estos conceptos se presentaron como objetivos y no problemáticos, sin tener en cuenta los matices de los criterios de medición contable, reconocimiento y revelación (Moerman \& van der Laan., 2007).

La investigación de tipo histórico de Irvine (2012), muestra el uso retórico de la contabilidad en una plantación de azúcar en el siglo XIX en Queensland, Australia, expresado en la visibilización de las utilidades y los costos laborales, con el fin de captar la atención de inversionistas; también de corte histórico, Bujaki (2010)evidencia como en la construcción del canal Rideau en Canadá, se acude al análisis de costos y beneficios mediante el CBA, utilizándolo unas veces como un recurso técnico y en otras como recurso retórico. Este último se da en el periodo previo a la construcción, en tanto el uso técnico ocurre durante el proceso de construcción. Por su parte, Hooper \& Kearins (1995) muestran en su artículo cómo el uso de estrategias de contabilidad creativa y la manipulación de la información contable, contribuyeron al ascenso y colapso de dos empresas de Nueva Zelanda. El artículo sustenta que la información financiera sirvió de apoyo al discurso de la fama repentina como expresión de iniciativa y de crecimiento.

Los anteriores trabajos permiten vincular la idea de la representación contable con la de la interpretación. Se concluye que el uso de las técnicas y la interpretación de sus resultados, están condicionados tanto por las características de los usuarios de 
la información, como por los intereses de quienes la emiten.

A manera de ejemplo la investigación de Collier (2006) evidencia la forma en que con fines retóricos, se orienta la contabilidad hacia la revelación de unos aspectos y el ocultamiento de otros en relación con los costos derivados de la actividad de la policía en Inglaterra. En las conclusiones, el autor sustenta de qué manera la aplicación no consiste en un enfoque metodológico que derive en una interpretación adecuada; por el contrario, se presenta un forzamiento en la aplicación de la técnica, como un uso tendiente a orientar hacia una interpretación, lo cual conduce a enfatizar en la delincuencia como la actividad económica de la policía, más que como un problema social con diversas causas, ocultando con ello su base económica y social.

Sobre la base de dos estudios de campo longitudinales en el sector minorista del Reino Unido, Free (2007) explora la forma en que las técnicas contables implicadas en la gestión de la cadena de suministro, tales como la contabilidad de libro abierto, la medición del desempeño y los controles, previsión y presupuestación, pueden, dependiendo del contexto, generar en unos casos, relaciones coercitivas (como premisa acusatoria de apropiación de recursos); y en otros, permisivas (susceptibles de solución conjunta de problemas, posibilidad de adaptación flexible, y de expansión de ventas y beneficios totales).

\subsubsection{Argumentación como opuesta a retórica}

Esta tendencia propone la existencia de una argumentación de tipo racional que apela a argumentos lógicos en contraste a una retórica que acude a sentimientos y emociones. Ignora esta tendencia que la retórica establece un continuum entre estos dos tipos de argumentos. Desde su origen clásico, la retórica integra argumentos lógicos derivados de una postura dialéctica que apela a los mejores argumentos, los más reconocidos y valorados entre las comunidades, con unos argumentos psicagónicos, que tocan las emociones del auditorio y mueven a la acción.
En esta línea, Nørreklit (2003) describe el énfasis persuasivo de los balances en Score Card, al soportarse solo en argumentos emocionales. Asimismo, pero enfatizando más en la poética estructural, se encuentra la investigación de Carter \& Cooper (2006), que analiza la relación entre forma poética y su fondo, como una manera de rastrear el impacto que este tipo de presentación tiene sobre el auditorio al acudir a una secuencia persuasiva que influye sobre el público, y en alusión a la metáfora Addison \& Mueller (2015) muestran el uso de las metáforas como estrategias retóricas para mostrar el lado oscuro de ciertas profesiones y, derivado de allí, evidenciar la distinción que se crea entre evasión y elusión y los encuadres retóricos que plantean alternativas a esta distinción.

Dentro de este campo hay una línea de acción que se orienta a analizar los diseños gráficos propios de la presentación de la información contable. En esta tendencia se destaca por el número de citaciones, el de Graves, Jordan \& Fleshes (1996), en el cual hace un análisis de cómo el diseño visual se constituye en criterio de verdad dentro de los informes contables, a partir de una lógica simbólica propia de la televisión. Este diseño simbólico se establece como criterio de verdad no solo en cuanto a la forma de presentar las imágenes, sino en los propios informes contables.

Brennan, Daly \& Harrington (2010) muestran cómo el énfasis visual se adapta a los atacantes y a los temas en defensa pública de adquisiciones hostiles. Por su parte, el trabajo de Courtis (2004) efectúa un estudio acerca de cómo el color se relaciona con el mayor o menor énfasis en revelar resultados positivos o negativos, y como este incide en las decisiones de inversión. Con un objetivo similar, aparece Hrasky (2012), quien establece una relación entre la mayor o menos sostenibilidad y el uso de imágenes en los informes de sostenibilidad. Llega a la conclusión de que las empresas con menos sostenibilidad acuden más a las imágenes que las otras que acuden más a los impactos reales.

Una variante de esta línea la constituye aquella en la cual las imágenes contribuyen a difundir ciertas concepciones del mundo. El trabajo de Amernic \& 
Craig (2000) presta especial atención al uso metáforas pictóricas desde una retórica visual dentro del plan de estudios de la enseñanza de la contabilidad financiera en la Web de IBM, llegan a la conclusión que la parafernalia visual de esta página, construye creencias y formas del discurso público. A pesar de que no enfatiza en las imágenes, un artículo posterior, analiza el uso de metáforas visuales en una carta conjunta, escrita por tres líderes del aluminio a nivel mundial, y entrega como resultado que este carta es elitista $y$, excluyente basada en supuestos que son consistentes con la extrema retórica del mercado "libre" (Amernic \& Craig, 2001). Por su parte, Baldvinsdottir, Burns, Nørreklit \& Scapens (2009) analizan la retórica de la imagen asociada a la figura del contador en los avisos publicitarios de software contable. Se muestra como estas imágenes han pasado de una idea de contrato responsable y racional, a una visión hipermoderna del contador hedonista.

Se destacan igualmente cuatro trabajos de Davidson (2008, 2010, 2014, 2015); en el primero de estos, se efectúa un análisis de las estrategias retóricas utilizadas en los informes contables, contando entre ellas algunas visuales sin que se centre específicamente en ellas; el segundo hace un análisis retórico de la imagen asociado a la constitución de la representación de los retratos de la élite empresarial; el tercero, propone un marco conceptual que permita un análisis de la retórica visual y lo centra en el análisis del discurso contable en torno al capital intelectual; el cuarto se centra en que en vista de las dificultades que tiene la contabilidad para representar los intangibles, los emisores del discurso contable apelan a la iluminación a través de las imágenes. Finalmente en el quinto, se engloba la producción precedente del autor al determinar las posibilidades alcances y campos investigativos de la retórica visual en relación con la contabilidad. Su alcance es el dar forma al campo de estudio propuesto revisando una amplia gama de temas y estableciendo diversas relaciones interdisciplinarias.

Matilal \& Höpfl (2009) sustentan cómo la fotografía puede contrarrestar la estrategia de ocultamiento de la contabilidad. La relación entre los aspectos eminentemente representativos de los estados contables y lo cotidiano vivido por quienes fueron directamen- te afectados por la tragedia de gas de Bhopal en la India en 1984; permite considerar la fuerza retórica de la fotografía en la captura de la tragedia y comparar esto con la posición adoptada por la Union Carbide en la contabilización de la catástrofe. El documento demuestra cómo las imágenes pueden complementar las acogedoras, coherentes y monológicas declaraciones de las cuentas y ayudar a conservar el carácter humano de los desastres. De igual forma el artículo de Pesci, Costa, \& Soobaroyen (2015) se centra en el uso de la repetición, tanto en narrativa y formas visuales, en los informes sociales y ambientales. Se investigan las formas de repetición como un recurso retórico adoptado por el preparador de un informe social y ambiental para ayudar al proceso de adquisición de conocimientos. Estos dos, son ejemplos que podrían, en ausencia de una lectura a profundidad, mostrar las opciones no hegemónicas de las retóricas visuales.

\subsubsection{Retórica como lenguaje sin correlato real}

Uno de los sentidos más recurrentes, no solo en el campo contable, sino en la cotidianidad, es el de la retórica como un discurso, engañoso o no, sin correlato con lo real. Más allá de su posible mentira, la retórica bajo esta mirada se ubica en tres posibles matices: Como un discurso alejado de una realidad empírica; como declaración de propósitos que no se cumplen ya sea por falta de interés, metodologías inadecuadas, o poco impacto de las aplicadas y como una especie de declaraciones de posibilidades de acción alcanzables mediante propuestas de implementación orientadas a lograr el cumplimiento de esas declaraciones, con el fin de que dejen de ser "retóricas". Es decir, al hacerse reales dejan de ser retóricas. Todo lo retórico se entiende como puro humo.

Un primer trabajo consultado basa el concepto en la discusión frontal entre el modelo explicativo cartesiano, y el modelo interpretativo aristotélico. McSweeney (1997) basado en la idea de que la ciencia explica hechos objetivos, emprende una discusión acerca de las posibilidades de representación de la contabilidad. Se contrasta la idea de explicación, como real y demostrable; a la afirmación, como propia de lo retórico. Lo cual también discute Armstrong (2006) al criticar las estrategias retóricas 
propias del discurso crítico, las cuales construyen ideología al alejarse de los aspectos empíricos de la cuestión y basarse más en el ideal.

Tal vez este sentido se vincule no tanto con el enmascaramiento, ni con la imposibilidad o incapacidad de materializar el discurso, sino con la disonancia que existe entre las declaraciones retóricas y la vida misma, como si la realidad social ofreciera resistencia a la configuración del mundo que se intenta ejercer desde el discurso. Por ejemplo, el caso de la implementación de la base de efectivo IPSAS en el sector Público Nepalí. Se llega a la conclusión que la supuesta popularidad de esta práctica es polémica al encontrase evidencias de su escasa utilización (Malmi \& Ikäheimo, 2003); el de la distancia entre la retórica de las auditorias de corte financiero en los procesos de toma de decisiones en las organizaciones, y las reales prácticas las cuales son mucho más dialógicas que lo que estas retóricas pretenden sustentar (Free, 2009); por último,la brecha que existe entre la retórica de la posibilidad de elección hospitalaria en los pacientes y la realidad en los casos de emergencia. Se ubica en el concepto de retórica como discursos insustancial (Dent, 2006).

En cuanto a la retórica como un discurso ajeno a la acción, Deegan (2012) llega a la conclusión de que hay un desacoplamiento entre la retórica de sostenibilidad social y las prácticas e intereses "reales" de las empresas de carbón australianas. Malmi \& Ikäheimo (2003) expone la diversidad en el uso real de la gestión basada en el valor con la ayuda de seis organizaciones con sede en Finlandia a partir de cinco industrias diferentes. Los resultados indican que para algunas organizaciones es meramente retórica, mientras que para otros parece tener un impacto tanto en la toma de decisiones y el sistema de control, tomando diversas formas de una empresa a otra. Con el fin de determinar el efectivo cumplimiento de las declaraciones en la acción, Seal (2014) analizó los impactos del BSC sobre la cultura organizacional de un banco. Se concluye que a pesar de su éxito en la coordinación de acciones, su impacto sobre los valores a largo plazo es ambiguo.

En esa misma línea, pero en el tono de la no materialización de un ideal, un artículo se centra en la rendición de cuentas de algunas Organizaciones no Gubernamentales para el Desarrollo en Irlanda (ONGD). Dicho trabajo concluye que el ideal de una rendición de cuentas basadas en la asociación, no pasa de ser una idea retórica que no se plasma en la aplicación ya que esta se mantiene en la línea de control y la justificación (O'Dwyer \& Unerman, 2007). En tanto otro con un interés similar propone procesos de rendición de cuenta en las ONGD que puedan contribuir sustancialmente a la realización de los elementos clave del enfoque basado en los derechos al desarrollo (O'Dwyer, 2010). Con la misma idea de mostrar la distancia entre retórica y realidad, Holloway (2004) trata un caso de planificación estratégica emergente en la Unversidad de Murdoch, en Australia, durante 2001; enfoque que, aunque se propone como alternativo, participativo y orientado a la discusión con el fin de minimizar las asimetrías, en su aplicación se observa que es un acto retórico sin correlato con la realidad.

\subsection{Hacia un concepto amplio de la retórica}

La retórica deliberativa está directamente involucrada en los usos políticos del discurso público. Su propósito es persuadir de lo conveniente y disuadir de lo perjudicial en determinados asuntos de interés común para el conjunto de la ciudad (Vega, 2013).

No se delibera sobre lo imposible ni tampoco sobre lo posible causal o natural, sino sobre aquello que depende de nuestra voluntad y que puede ser de otro modo. El discurso acerca de lo bueno y lo malo, lo útil y lo inútil, lo justo y lo injusto constituye el objeto de la retórica deliberativa aristotélica. La retórica permite que los seres humanos puedan razonar sobre su actuación, coordinándola mutuamente y buscando fines comunes. En este sentido, es posible afirmar, desde una perspectiva aristotélica, que la retórica es esencial al ejercicio de la ciudadanía. La retórica posee una clara dimensión política, social, ciudadana: el arte retórico debe ser útil para el ciudadano. Se comprende así la gran importancia de la retórica, y más en una sociedad preocupada por defender la polis, que es tarea de todos los ciudadanos. Se entiende pues la retórica como una facultad humana general indispensable para la convivencia política (Vega, 2007). 
Pese a las variaciones posibles de la retórica, existen algunos elementos de su origen que permanecen invariables. La orientación hacia el auditorio sin que haya un contexto de intercambio (los modelos de diálogo no son objeto de la retórica sino de la dialéctica) (Plantín,2004), esta se expresa en tres situaciones típicas del discurso: la asamblea, el tribunal y las reuniones conmemorativas (Ricoeur, 1970, citado por Ruiz, 2014); la puesta en escena de una argumentación por la insuficiencia de información disponible en un contexto de incertidumbre marcado por la urgencia (Plantín, 2004) por lo cual es un discurso orientado a la acción (Ricoeur, 1970, citado por Ruiz 2014); el carácter probatorio que se orienta a la aportación de la mejor prueba que, de acuerdo con Ricoeur (1970, se aplica ante la pretensión de hacer prevalecer un punto de vista sobre el opuesto; esta controversia requiere tomar una decisión tajante.

Si bien las situaciones típicas se han ampliado, es necesario enfatizar que la retórica se orienta a hacer prevalecer un punto de vista ante un tercero que no actúa como contraparte sino como juez. De allí que se parta de la adaptación del discurso al auditorio con el fin de partir de aquellos valores, creencias, conocimientos compartidos, formas de comunicación y prácticas reconocidas por ese auditorio; esto permite trasferir la aceptación de las premisas a la aceptación de las conclusiones. Esto connotaría que incluso la demostración, se subordina a esta conciencia retórica, en tanto apela a la convicción que es propia de la argumentación dirigida a un auditorio universal (Ricoeur, 1970, citado por Ruiz, 2014).

De Souza (2000) sintetiza lo anterior, al afirmar que la retórica parte de premisas probables, para llegar a conclusiones probables; las premisas como punto de partida se fundamentan en dos posibilidades: los hechos y las verdades, y los topoi.

Hechos y verdades gozan de tal aceptación, que no necesitan argumentarse. No obstante existen hechos que van perdiendo su carácter de absoluta verdad, en tanto otros son presentados como tales por vía de la naturalización; asunto que en el campo contable es evidenciado en muchas de las presunciones del pensamiento único (Gómez, 2007).
Por su parte los topoi "son "lugares comunes" puntos de vista ampliamente aceptados, de contenido muy abierto, inacabado o flexible y fácilmente adaptables a diferentes contextos de argumentación" (De Souza, 2000, p. 111). Para Walter Ong citado por De Souza (2000, p. 111): "En todos los sentidos el término tiene que ver de alguna u otra forma con la exploración de lo que ya es conocido, $y$, muchas veces, de lo que ya es extremadamente bien conocido". El conjunto de los topoi dominantes, marca el clima hegemónico de cada época y subordina los otros, los cuales son vistos como marginales o presentados como discursos contrarios.

Muchas de las hegemonías surgen de la Hobbesiana cesión del dominio de lo social a una comunidad experta, asumida como la única con la posibilidad de decidir sobre los destinos de una comunidad; "este juego puede desplazar la decisión comunitaria al poder de unos sujetos que se han sometido a unas reglas que, a su vez, han sido construidas para definir "el lugar" de la verdad, al final, en ese juego, los expertos se auto legitiman" (Vargas \& Cárdenas, 2005, p. 83).

De acuerdo con Arendt (2009) el ansia acumulativa de la Edad Moderna, catapulta la lógica de la expropiación como base para una acumulación cada vez mayor, y con ello, se disemina la condición de servilismo que tanto afecta la posibilidad de participar en lo público. A partir de allí, la esfera social se convierte en un elemento que protege la propiedad privada producto de la acumulación.

La sociedad, cuando entró por vez primera en la esfera pública, adoptó el disfraz de una organización de propietarios que, en lugar de exigir el acceso a la esfera pública debido a su riqueza, pidió protección para acumular más riqueza (Arendt, 2009, p. 73).

Con ello se crea una comunidad de privilegios que se arrogan el destino de lo público. Este ha sido el aspecto nodal de la crítica retórica en Contabilidad. En primer lugar, el hecho de que se presuponga un auditorio limitado para la información contable, restringido a accionistas e inversionistas, acreedores y al Estado; limita el poder comunicativo y político de la Contabilidad. 
Segundo, el pensar lo público en función de la opinión pública, deriva en la definición de los valores $e$ intereses de determinados auditorios particulares, como la representación de valores universales. Se hace creer de esta forma que los intereses del capital representan los intereses de una sociedad y que los valores que estos pregonan: éxito, competitividad, racionalidad, etc. legitiman las acciones de las empresas. En otras ocasiones, en virtud de las presiones de esos otros grupos, o de las exigencias sociales, se da un intento de conciliación por vía de estrategias como las presentadas en la revisión precedente.

\subsubsection{La retórica como ejercicio crítico}

No obstante, no es posible asumir que por tales razones la retórica es privilegio exclusivo de los grupos hegemónicos. En primer lugar, porque los hechos y topoi establecidos, no tienen porque permanecer así. Eso permite establecer la diferencia entre la nueva retórica de Perelman \& Olbrechts Tyteca (1989); y la Novísima Retórica, propuesta por De Souza (2000). Los primeros adoptan posturas estratégicas al justificar los cambios solo sobre la base de valores previamente admitidos, privilegiando la conservación de lo establecido como garantía de éxito; el segundo asume la actitud dialéctica de oponer un topoi al otro; de proponer un hecho frente a otro establecido (De Souza, 2000).

Esto da una gran preminencia al aspecto dialéctico de la argumentación, pues permite una selección de lo verosímil frente a lo engañoso, de la apariencia del conocimiento frente al mismo conocimiento. La dialéctica se constituye así en un arte: arte de la selección de los argumentos, de su revisión y organización. Arte que difiere del simple sentido común en tanto implica la elaboración de estos a partir de principios de racionalidad que se acercan a la demostración sin ser ella.

La retórica se inserta en una teoría de la praxis que se conecta con la ética y la política, "según la primera, la retórica mueve a los hombres a actuar buscando el bien; de acuerdo con la segunda, convence al otro o a otros (a veces a la mayoría e incluso a todos) de procurar aquello que se ha visto como lo que redundará en beneficio de la polis"
(Beuchot, 1998, p.12). Este ideal según Beuchot (1998) exige un vínculo entre la razón y la emoción, pues la sola racionalidad no mueve a la acción.

Al ser la persuasión un discurso orientado a la acción, es imposible desvincular esta de las pasiones, pues la razón puede lograr el asentimiento y la comprensión, pero sólo el deseo moviliza la voluntad.

A este componente emocional, Aristóteles lo denominó el elemento psicagónico de la retórica; este es interpretado como una especie de psicología proyectada, una configuración de la idea del otro que sirve de punto de partida para la persuasión (Barthes, 1993). Es el punto débil de la propuesta de $\mathrm{Pe}^{-}$ relman \& Olbrechts Tyteca (1989), quienes afirman que la cena se sirve al gusto de los comensales, no del cocinero (1989). Con ello adaptan su discurso exclusivamente a los intereses y valores del otro, dejando de lado las propias convicciones y creencias. Es necesario coincidir con De Souza (2000) que esta es una mirada estratégica de la persuasión.

Ricoeur citado por Vargas \& Cárdenas (2005) cuestiona a Perelman (1997) por desconocer el lugar del propio deseo y de la sensibilidad como componentes de la persuasión. Al expulsar el deseo y la emoción del campo de la razón, está convirtiendo a este en un acto irracional, y por lo tanto generador de violencia. De igual forma convierte a la razón práctica en un acto meramente estratégico, alejado del deseo connatural al hombre por lo bueno, lo justo y lo bello.

Con el aspecto lógico y dialectico de la retórica, el ser humano se inscribe en relación con unas ideas pero esta adhesión producto del conocimiento no es suficiente, es necesario que se vincule con el deseo. Emerge el concepto de lo preferible que connota una elección entre varias posibilidades, una selección con arreglo a valores, deseos e intereses; y un compromiso de comunicar eso preferible, no solo a partir de los propios intereses, sino de la conciencia de lo bello, lo bueno, lo justo.

La apelación a los intereses implica un sentido ético, en tanto demanda la selección de aquellos que sean preferibles, que deban prevalecer en determinadas 
situaciones. Los intereses como bien lo indica Martínez citado por Jiménez (2012, p. 224), pueden estar vinculados a condiciones subjetivas propias del direccionamiento personal u objetivas que "pueden en el sujeto ser reflejo de las circunstancias dadas en el mundo exterior, tales como el marco sociocultural, las condiciones en que se desarrolla la vida y muchos otros factores que inciden en las direcciones que opte el interés particular del sujeto". Llama la intención que el carácter objetivo del interés no radica en una abstracción o en una determinación reificada, sino que sumado a unas relaciones materiales, tiene una matriz intersubjetiva que lo constituye. De allí que Jiménez (2012) derive el concepto de responsabilidad social como el entramado de responsabilidades que cada grupo de interés tiene consigo mismo y con la comunidad en la cual se halla. Por lo cual la responsabilidad social no debe ser de empresas, sino de los diversos actores que se relacionan con estas.

Para Sen citado por Ruiz (2014), las decisiones sobre el destino y la sostenibilidad humana no pueden expresarse únicamente en la satisfacción de necesidades humanas, por considerar este tipo de criterios como actitudes pasivas que no se soportan en ningún criterio de racionalidad diferente al del propio interés. De esta forma la necesidad de conservación surge de la exigencia del lugar de lo precario, de la necesidad de preservar aquello que es valioso por su misma condición de fragilidad y por la potestad que tenemos de protegerla. Es un acto de responsabilidad que expresa la capacidad y libertad para pensar, valorar y actuar.

Desde el punto de vista de la contabilidad, se exige pasar de una concepción monetarista del valor representada en cantidades, a una discusión social en torno a lo que tiene significado y es apreciado. "Así, las valoraciones contables no pueden verse como datos, simplemente expresados en soportes de transacciones o de datos del mercado, sino como evaluaciones sociales de lo colectivamente apreciado, deseable en fin...de lo bueno" (Gómez, 2007, p. 41). Lo cual convierte a la Contabilidad en una disciplina moral que supera el valor de la cantidad como garante supremo de la verdad, y rescata el valor de la cualidad.
Entonces, al pensar el papel de las emociones en la retórica, no solo deben interpretarse como el arsenal para mover la voluntad del otro; deben entenderse como la base para asumir posiciones morales dentro de la deliberación; superando con ello el aspecto neutralizador de la lógica racional. En el marco de lo preferible, las pasiones se convierten en el fuelle que enciende la búsqueda de una mejor sociedad. La retórica sólo abandonará sus posibilidades estratégicas si las pasiones dejan de estar al servicio del logro de un objetivo estratégico, en cuyo caso conducirían a la manipulación, y pasan a convertirse en el deseo por lo bello, por lo justo y por lo bueno. En la búsqueda de un mejor mundo para todos, en la convicción de que hay algo distinto, algo posible, algo mejor.

En definitiva, la retórica integra una doble significación como "arte político" representada en su uso, y como epistemología materializada en la reflexión sobre la misma. Por lo tanto un sujeto retórico no es sólo un sujeto de acción, es un sujeto de reflexión sobre las condiciones de aceptabilidad de los argumentos, lo cual debe superar visiones estratégicas en función de los objetivos, para apalancarse en condiciones de aceptabilidad y validez de los argumentos.

\subsubsection{Acerca del lenguaje}

Grize (2004, p. 50) centra en las pasiones la diferencia entre convencer y persuadir: según él, la única forma posible de conducir a la acción es trasformando los valores, y esto no se logra solo sobre la base de la razón: "los sentimientos forman parte de nuestras actividades diarias tanto como la razón y una argumentación no puede limitarse a apelar tan solo a la inteligencia, debe conmover". Las pasiones generan la disposición necesaria orientada a la acción. En esta disposición, tiene gran influencia el lenguaje. Para lograr mover a la acción desde la comunicación se debe pasar de una intención comunicativa del "hacer saber" al "hacer ver", lo que se consigue por medio de figuras discursivas. "Es una determinada visión de las cosas la que pone en movimiento la voluntad. El pathos se une así al logos. Los objetos del discurso deben ser iluminados, lo que implica poner en evidencia algunas de sus facetas y ocultar otras" (Grize, 2004, p. 50). 
Niamh \& Merckl Davis (2014) acerca de la disputa entre Greenpeace y las empresas de ropa deportiva con asiento en China, efectúan una documentada explicación acerca del papel de la metáfora en las discusiones sociales. No sólo son dispositivos conceptuales potentes, por indicar formas particulares de pensar un problema y de estructurar la realidad, sino que refuerzan las percepciones específicas y formas de pensar sobre un tema, ignorando otros. Actúan así como una ingeniería de la percepción. Además son indicativas de los valores y creencias subyacentes en los actores sociales. Proporcionan una visión de los supuestos que subyacen a una reclamación o declaración hecha en un tema en particular.

Las metáforas desempeñan un papel fundamental en la construcción y reproducción de las ideologías y justifican la acción social y el comportamiento. El lenguaje, el significado y el poder están vinculados entre sí. Por esta razón, "el uso de metáforas asociadas a ideologías dominantes afectan nuestra forma de pensar y actuar, lo que refuerza la desigualdad social, la injusticia y la explotación del medio ambiente" (Llewellyn, 2003, citado por Niamh \& Merckl Davis, 2014, p. 612). Sin embargo, las metáforas no solo cumplen una labor reproductiva, también pueden cumplir la labor crítica de transformación de ese universo conceptual, pueden romper ciertas nociones o creencias aceptadas naturalmente.

Para Perelman (1997), en la Edad Media la retórica perdió contacto con la dialéctica y se centró exclusivamente en el culto por el lenguaje bello y adornado. Tal división redujo las figuras literarias a un fanal aislado en el cual el lenguaje pierde todo poder de argumentar. Pero con la reivindicación de la retórica, reivindica el poder argumentativo que tienen las figuras retóricas, sobre todo cuando en su uso de rompen ciertas cristalizaciones de las figuras con el fin de devolverles a estas su poder transformador. En última instancia, la relación del sujeto con el lenguaje debe permitirle abrirse a nuevas interpretaciones de la realidad. De allí deriva la diferencia entre un logos pedagógico que incita a pensar y otro que transmite lo ya pensado. O en palabras de Deleuze citado por Larrosa (2003), entre los encuentros de reconocimiento, que están llenos de sí, y los que fuerzan a pensar, aquellos que por vía de la sensibilidad conmueven el alma y la dejan perpleja.

De acuerdo con Beristaín (1995, p. 421) el carácter pedagógico de la retórica, en sus orígenes, procuraba un fundamento moral del educando ya que "para dominar el arte de hablar bien, se requiere pensar bien y para pensar bien, es necesario vivir bien. Y sin todo ello no es posible conmover, ni convencer, por lo tanto tampoco es posible persuadir". De acuerdo con Siles Ruiz (2012) la palabra es la base de toda democracia, pues, sin ella, no hay diálogo ni tampoco hay ley. El modo de hacer lo más perfecto posible ese diálogo y esa ley a la que llegan, por acuerdo mutuo y después de debatir los hombres, fue "la retórica, que enseñaba a articular la relación entre las palabras y las cosas, buscando en el discurso lo bello menos que lo justo y, si era posible, la conjunción en la realidad y en el lenguaje de los dos" Siles Ruiz (2012, p. 30).

\subsection{La retórica como ejercicio contrahege- mónico}

Para empezar se sintetizan dos elementos propios de la retórica clásica: el hecho de que acompaña el ejercicio propio de la ciudadanía y por lo tanto no solo se orienta a develar los resortes propios del discurso del poder; sino que es un poder en sí mismo que se puede usar con fines contrahegemónicos; y el reconocimiento de las propias pasiones como fundamento de una discusión moral propuesta desde lo preferible. En esta sesión se discuten algunas propuestas, escasas, que en la literatura contable se orientan a reivindicar estas posibilidades de la retórica.

\subsubsection{La ubicuidad de la retórica}

Se alude incialmente al trabajo de Arrington \& Schweiker (1992), quienes afianzados en el carácter público y social del conocimiento científico, plantean que el conocimiento, la razón, la racionalidad e incluso la legitimidad empírica dependen de prácticas intersubjetivas que operan al interior de las comunidades investigativas (Diesing, 1962; Brown, 1987; Garfinkel, 1967; Latour \&Woolgar, 1979; citados por Arrington \& Schweiker, 1992). 
En ese sentido, más que una realidad contra la cual hay que luchar, la retórica se considera ubicua a la investigación contable. No obstante, llama la atención la indiferencia y el desprecio que se tiene frente a esta en el campo contable. Desprecio que ha estado presente desde su origen y que ha acompañado a la retórica en su devenir histórico. Aún así, destaca el fortalecimiento de los estudios retóricos desde diversos campos.

El desarrollo de su artículo parte de la aceptación de que toda investigación presupone un público destinatario del discurso científico, lo cual incide sobre tres asunciones del conocimiento: la materia objeto de la investigación, las decisiones acerca de cómo comunicar ese conocimiento y la alineación a los valores, tanto en cuanto a los fines de la contabilidad, como en los de la investigación contable.

En cuanto al objeto materia de investigación, se plantea que la riqueza de interpretaciones acerca del sentido de la contabilidad, conduce inexorablemente a que cualquier reclamo de inteligibilidad del conocimiento contable sea necesariamente parcial. En adición, esto conduce a una gran prolijidad de grupos de investigación con diversos intereses, alcances y resultados. Cada uno de ellos enarbola sus propias metáforas: la contabilidad como la historia, como la información, como lenguaje, como política, como mitología, como ideología y como dominación y explotación. Metáforas que dan cuenta de las riquezas de las prácticas sociales tales como la contabilidad. Todas dan cuenta de un proceso de selección de la realidad, y ninguna abarca en sí misma la complejidad de la realidad que pretende nombrar (Arrington \& Schweiker, 1992).

Más importante aún, diferentes comunidades tienen diferentes posturas hermenéuticas sobre el fenómeno de contabilidad -diferentes formas de interpretar y comprender lo que la contabilidad es y lo que no es. Si se trata de persuadir a una audiencia de que lo dicho merece el estatus honorífico de conocimiento, se debe configurar la contabilidad de una manera sensible a la forma de la hermenéutica del público objetivo. Por ahora, baste decir que hay una infinidad de posturas hermenéuticas que podrían ser ejercidas sobre las decisiones acerca de cómo con- figurar la contabilidad como un tema (Arrington \& Schweiker, 1992).

Obviamente esto incide sobre el segundo aspecto: las formas de comunicar el conocimiento. Algunas comunidades de investigación toman la producción de la contabilidad como un hecho; otros, los teóricos críticos o positivos teóricos, por ejemplo, están más interesados en los procesos históricos que dan lugar a la contabilidad, en tanto "los teóricos de ingresos "normativos", transcienden la contabilidad distanciándose de lo concreto, de las limitaciones empíricas de la producción de contabilidad, con el fin de escribir exclusivamente en el dominio ideacional - de lo que la contabilidad debe ser a la luz de su creencias sobre el "mejor" de los mundos posibles" (Arrington \& Schweiker, 1992, p. 519).

Tales pretensiones inciden directamente sobre el estilo de escritura. Los teóricos normativos promueven un género trascendental, un estilo especulativo algo así como la poesía romántica en la medida en que expresa un anhelo de una contabilidad idealizada sin enfrentarse a las restricciones de la situación económica y social. Los contadores marxistas a menudo escriben como Charles Dickens o como los realistas americanos de la década de 1930; historias de gente común sufrimiento por razones económicas (y contables). Algunos, los que escriben para los profesionales, permanecen en el género de los manuales técnicos de ingeniería, interpretan la contabilidad como si estuviera gobernada por una racionalidad tecnicista producto de una realidad dada y no problemática (Arrington \& Schweiker, 1992).

Finalmente, en cuanto a la alineación a los valores, hoy es insostenible la postura de una investigación objetiva libre de valores. Existe en la investigación contable un alto grado de valoraciones morales, expresado en términos con fuerte connotación moral, tales como derechos, responsabilidades, bienestar, progreso, riqueza, etc. Conceptos que lejos de ser unívocos adquieren diferentes sentido desde las disciplinas y desde los marcos de interpretación. Así mismo, existen valores académicos que se esgrimen como criterio de legitimidad. Por ejemplo, el telos de la predicción está presente en las investigaciones 
de tipo positivista; en tanto las que se declaran críticas han de esgrimir necesariamente el telos de la emancipación.

Lyne (1990) citado por Arrington \& Schweiker (1992) concluye que estas discusiones derivan en el vínculo entre la hermenéutica y la retórica, vínculo que Ricoeur (1970) había propuesto. La retórica ayuda a recuperar la función del autor en la teoría hermenéutica en la medida en que llama la atención sobre las acciones del autor tendientes a anticipar un auditorio o comunidad de lectores.

La comprensión de la realidad y su consecuente comunicación, surge entonces como una historicidad que radica en ir trasformando las interpretaciones del mundo, en ir estableciendo un proceso de reconfiguración de la propia subjetividad a partir de la reconfiguración del sentido que construimos en nuestra relación con la realidad.

\subsubsection{Greenpeace,y las lavanderías sucias}

Niamh \& Merckl Davis (2014) afirman que la tradición en los estudios retóricos parte del supuesto de que la construcción de la legitimidad en los aspectos ambientales está a cargo de las organizaciones, convirtiendo así al público en un auditorio de estas prácticas de legitimación. El artículo plantea por el contrario, la construcción de la legitimidad como un proceso de influencia recíproca logrado mediante el diálogo social (Ginzel et al, 2004, citado por Niamh \& Merckl Davis, 2014 ).

El foco del análisis es el uso de la retórica y la argumentación como medio de resolución de un conflicto entre Greenpeace,y empresas de la industria de la moda de ropa deportiva, en relación con la contaminación del agua en China.

La investigación sugiere que el uso de la retórica y la argumentación se manifiestan sobre todo en controversias públicas, conflictos sobre valores o insuficiencias en el desempeño social y ambiental de las empresas, ya que las organizaciones dependen de la aprobación del público. Distinguen entre las partes interesadas que tienen un derecho legal o moral de las organizaciones y grupos de interés que tienen la capacidad de influir en los comportamientos organizacionales, procesos o resultados. Los primeros consisten en los empleados, acreedores, y proveedores de capital. A los segundos también se les conoce como 'stakeseekers' (Fassin, 2009, citado por Niamh \& Merckl Davis, 2014) buscan tener una entrada en los procesos de toma de decisiones organizativas, incluyen a las ONG, grupos de presión y los movimientos sociales. Las ONGs ambientalistas, como Greenpeace, y el Fondo Mundial para la Naturaleza, tratan de influir sobre la organización en actividades ambientales, en el desempeño y en la presentación de informes.

Básicamente reitera la idea de que las organizaciones utilizan la retórica para mantener sus ideales hegemónicos capitalistas. Por vía de acciones retrospectivas que responden a situaciones retóricas preexistentes o por vía proactiva que las anticipan. En ese sentido se utiliza la retórica para fabricar el consentimiento por medio de los discursos dominantes. Su papel estratégico pretende convencer acerca de la solidez financiera, la responsabilidad social y la alineación con los valores de una sociedad, todo con el fin de lograr sus intereses.

Sin embargo, existe poca investigación sobre el uso de la retórica de los actores poderosos, como Greenpeace, Amnistía Internacional y el Fondo Mundial para la Naturaleza, como un medio de persuadir a las organizaciones para que revisen sus valores o mejoren su desempeño social y ambiental. En el caso de un conflicto abierto entre una organización y una parte interesada, el objetivo es convencer a la otra parte y a los públicos pertinentes, incluidos los medios de comunicación, de la validez de un punto de vista o de la necesidad y legitimidad de un determinado curso particular de acción (Niamh \& Merckl Davis, 2014).

La investigación analiza los comunicados de prensa tanto de Greenpeace,como de las empresas de ropa deportiva. Entre los hallazgos significativos, se menciona que mientras Greenpeace, remite sus comunicados a los activistas, consumidores, encargados de políticas ambientales y los medios de comunicación; las empresas de moda los dirigen a Greenpeace, y a sus proveedores. 
En cuanto a los tipos de argumentos, se encuentra en la investigación que desde el logos, ambas partes acuden a la retórica de la ciencia, algo muy propio de las discusiones ambientales. Pero mientras Greenpeace, acude a un lenguaje que evoca una respuesta emocional "disruptores hormonales bioacumulativos", las empresas acuden a un lenguaje más técnico "nonilfenoletoxilatos", "alquilfenoles", "alquilfenoletoxilatos". Desde el punto de vista del ethos, la apelación a la ley y el respeto a la misma define la pulcritud en la imagen. Lo mismo la apelación a la autoridad como base para legitimar las afirmaciones. El contraste es que Greenpeace, utiliza poco la retórica de la ley o las auditorías, en tanto las empresas se amparan muchas veces en las regulaciones locales para justificar sus acciones. Lo cual desconoce que "la legitimidad organizacional va más allá de lo legal e incluye adecuación a unos valores y creencias socialmente aceptados" (Suchman, 1995, citado por Niamh \& Merckl Davis, 2014,). De allí que el gran debate iba más allá de la acusación de delito y tocaba una discusión acerca de la legitimidad de la organización y su respeto a un sistema de creencias y valores.

Desde el punto de vista del pathos, la acción metafórica se orientó por Greenpeace, a partir de la simple expresión "trapos sucios", la cual convoca la idea de lo que se lava en casa, como algo que se esconde con la consecuente apelación a lo corrupto. Este efecto pathico se incrementa con las alusiones al tamaño de la empresa: "monstruo", "gigante", "monopolio", etc. A esto las empresas respondían con argumentos desde la ciencia y desde la ley.

Greenpeace, utiliza las metáforas capitalistas asociadas a la competitividad, el progreso y su correlato con el deporte, en contra de las organizaciones, al invitarlos a ser los "primeros en ganar esa competencia", al llamar "rezagados" y "perdedores" a las empresas que no se comprometieran. Toda esta retórica impacta a las empresas por ver en riesgo su legitimidad. Frente a este recurso las empresas hacen lo mismo al acudir al concepto de "cooperación", "viaje", "trabajo en equipo", "proceso lento y madurado". Metáforas de la lentitud que evocan algunos de los principios de los grupos alternativos, con ello pretende ganar tiempo y hacer ver el proceso como tortuoso.
En conclusión, tanto Greenpeace, como las empresas de ropa deportiva, utilizan metáforas que incorporan valores de la otra parte para convencerlos de la validez y legitimidad de su argumento (Niamh \& Merckl Davis, 2014).

Los hallazgos permiten concluir que el resultado de conflictos sobre cuestiones sociales y ambientales depende de los atributos particulares de las partes involucradas interesadas y la capacidad de las partes interesadas para aprovechar el poder y la legitimidad de otras. A Las empresas les resulta difícil ignorar las demandas de los grupos de interés poderosos y legítimos que tienen reclamaciones urgentes. De igual forma, los autores concluyen que en los conflictos sociales y ambientales, el acceso a los recursos financieros es menos crucial que la capacidad de acceder a una red de apoyo de otros grupos de interés clave, como partidarios, consumidores, público en general y los medios de comunicación, aprovechando eso sí las habilidades retóricas propias de las relaciones públicas. Finalmente, El uso de metáforas permite a las partes involucradas en el conflicto enmarcar y replantear la cuestión controvertida de manera particular, desempeñando así un papel clave en la forma en que el conflicto se resuelve (Niamh \& Merckl Davis, 2014).

El texto aporta elementos valiosos que permiten entender la retórica al servicio de la deliberación social. Si bien es cierto que esta ha estado al servicio de intereses hegemónicos, es necesario indicar que también puede estar al servicio de la crítica y de la presión hacia las organizaciones aprovechando las necesidades de legitimidad que estas tienen, y acudiendo a diversos grupos de interés.

Desde este punto de vista, es valioso el reconocimiento de los diferentes auditorios, sus valores $e$ intereses. Al respecto, la clasificación de auditorios desde el punto de vista del poder, la legitimidad y la urgencia (Niamh \& Merckl Davis, 2014), provee elementos vitales para entender de qué manera la retórica se convierte en un medio de constituir los recursos simbólicos que otorgan o no legitimidad a las organizaciones y convierten al discurso en un recurso fundamental dentro de la deliberación social. De esta forma los grupos contrahegemónicos 
ejercen la presión necesaria con base en su poder y legitimidad, pero acudiendo a la urgencia como medio para movilizar la acción.

En este contexto, los diferentes agentes o grupos de interés actúan como el auditorio al cual se dirige el discurso a pesar de que este se orienta al debate cara a cara. Pero al ser un debate difundido en medios de comunicación, tiene el poder de apelar a los factores de credibilidad propios de la argumentación (argumentación desde el logos mediante la retórica del discurso científico), a argumentos mediante el ethos (basados en la legitimidad de la prueba o en la legalidad de la acción para el caso de las empresas); pero sobre todo a los argumentos mediante el pathos, merced al uso de las metáforas como elementos que logran visibilizar algunos aspectos, generar adhesión y establecer esa ley de paso que partiendo de la concesión de unos valores socialmente aceptados(competencia, progreso $y$ avance), lo cual obliga a transformar prácticas bajo el reconocimiento de otros valores que no se proponen como contradictorios sino como complementarios. Tal es el caso de las metáforas de la velocidad y la competencia, asociados a la urgencia de emprender lo antes posible los cambios en las prácticas de producción que están generando contaminación en China, bajo el riesgo de quedarse atrás en la carrera por un mundo mejor.

Es necesario recalcar la diferencia entre argumentación y persuasión. La primera tiene un carácter marcadamente racional, y se orienta hacia la discusión. Pero la segunda tiene un carácter más emocional y su objetivo fundamental es incitar a la acción. En este caso la retórica de Greenpeace, al tener varios auditorios tiene diferentes propósitos: busca por un lado que las empresas acepten los hechos, acepten la responsabilidad y modifiquen sus prácticas, busca que el público incremente sus mecanismos de presión y generen un activismo fuerte y pretende que los entes reguladores y estados modifiquen las regulaciones existentes. Sin embargo, queda una duda acerca de esta actitud retórica, la cual sigue siendo estratégica al usar los medios como base para lograr unos fines que no se discuten por parte de Green Peace. El hecho de que las metáforas se centren en la lógica capitalista del progreso y la competencia, tiene un gran poder persuasivo, pero hace poco a favor de la transformación de unos valores sociales. En ese sentido se aleja de la pretensión de una persuasión centrada en la racionalidad (De Souza, 2000) y en el pathos de lo deseable, lo bueno, lo justo (Nussbaum, 1996). Al no salirse del escenario de las lógicas propias de las organizaciones, se convierte en una forma de reproducirlas.

Ante lo anterior, es posible establecer un matiz, al afirmar que de todos modos las discusiones están insertas en una suerte de juegos estratégicos: En la relación de fuerzas que implica cualquier posición discursiva, se presentan " juegos (games) estratégicos de acción y reacción, de pregunta y respuesta, de dominación y también de lucha) El discurso es ese conjunto regular de hechos lingüísticos en cierto nivel y polémicos y estratégicos en otro (Foucault, 1973, citado por Ruiz, 2014, p. 118).

Por lo tanto, en esa lucha, en ese juego de dominación y resistencia empiezan a aflorar los criterios de determinación de la verdad y validez del conocimiento. El cual no responde a criterios inmanentes ni universales, sino que "este es cada vez el resultado histórico y puntual de condiciones que no son del orden del conocimiento" (Foucault, 1973, citado por Ruiz, 2014, p. 12).

Lo cual dentro del texto también se reitera al aludir la idea de Bourdieau (1991, citado por Niamh \& Merckl Davis, 2014), acerca de que el lenguaje es un mecanismo de poder a través del cual los constituyentes persiguen sus intereses.

\subsubsection{La contabilidad al servicio de una retórica socialista}

Gallofer \& Haslam (2006) justifican la importancia de una historia crítica de la contabilidad. Argumentan que "el análisis histórico puede ubicarnos la contabilidad en las dinámicas sociales y políticas, y nos ayuda a comprender y elaborar el carácter problemático general del funcionamiento social $y$ político de la contabilidad" (Gallofer \& Haslam, 2006, p. 225). De esta forma no solo es posible mirar cómo ha cambiado, sino también qué perspectivas de futuro se abren. 
Dentro de sus referentes teóricos remiten a Gramsci, Althusser \& Hall citados por Gallofer \& Haslam (2006) subrayan la importancia de los medios de comunicación generalmente como órgano hegemónico de la opinión pública, de forma que las clases dominantes construyen consenso mediante la activación de las relaciones con diversas fuerzas sociales. Destacan el que Gramsci haya llamado la atención sobre el carácter incompleto de la hegemonía y haya destacado la forma como trabajan las fuerzas de clase, desde acciones sociales progresistas y revolucionarias.

Así que emprenden un análisis de las comunicaciones contables en el contexto de un semanario publicado por el movimiento radical Red Clydeside, en Glasgow, Escocia. La región de Clyde, era un centro de actividades contra-hegemónicas y socialistas durante la primera guerra mundial. Esto constituye un contexto de crisis de la dinámica social y de importantes y dramáticas tensiones sociales y políticas. Las fuerzas hegemónicas fueron amenazadas por la guerra y por las tendencias contrahegemónicas socialistas. Lo cual coincide con las ideas de Berinstaín (1995) acerca del papel dinamizador que tiene la retórica en contextos de crisis.

En medio de un contexto de descenso de la productividad, congelamiento de salarios, exacerbación de las tensiones sociales y la crisis como producto de las especulaciones surgidas en la primera guerra mundial, surge el semanario Forward, fundado por Thomas Johnson, quien desde una postura socialista consideraba que era importante educar a la clase obrera en la lucha social a través de la presentación de hechos que evidenciaran las desigualdades sociales, con el fin de cambiar un sistema opresivo $e$ injusto. Algunos de los temas que abordaba eran la crítica a los aumentos de alquiler y precios de los alimentos; beneficios de las empresas derivados de la especulación de la guerra, la estrecha relación entre empresas públicas y privadas y la alineación de la iglesia oficial con los intereses capitalistas.

En relación con la especulación producto de la guerra, se empeñó en mostrar al capitalismo internacional como los ganadores beneficiados de la misma. Se moviliza la retórica socialista conviertiendo la información contable en hechos sencillos, con base en los informes anuales de las empresas, los anuarios de las bolsas y los discursos de la prensa hegemónica, muy centrados en la lógica del resultado contable. La principal estrategia era utilizar los números de esta información para apoyar la crítica socialista.

Un ejemplo que se cita tiene que ver con un informe de The Economist acerca del rendimiento de varias empresas, agrupado mediante datos estadísticos. The Economist hace uso de los datos contables para que apunte a una "continuación del debilitamiento del ritmo de aumento de los beneficios que ha tenido lugar desde la introducción del exceso de cargas de beneficios sociales" (Gallofer \& Haslam, 2006, p. 237). Por el contrario el artículo de The Forward, muestra con las mismas cifras que "el saqueo" se incrementó con respecto al año anterior. En su informe pone el énfasis en las empresas que más se beneficiaron, contrario a The economist que lo pone en las que menos, y recalca como los beneficios netos se logran después incluso del pago de honorarios de los directores, tipificado desde la retórica socialista como los que más se benefician de la explotación de los trabajadores.

Lo más convincente radica en la relación que hace entre las empresas con mayores utilidades (té, caucho, empresas de hierro y carbón y empresas de acero) y el aumento en los precios, mostrando así como las empresas que tuvieron mayores utilidades en los dos últimos años, coinciden con aquellas que aumentaron sus precios. Remata concluyendo en un tono apelativo:

Así que hay que añadir los beneficios de los dos años para tener una idea del colosal saqueo que está pasando, y una explicación de a dónde van a parar los precios crecientes (The Forward, 1917, citado en Gallofer \& Haslam, 2006, p. 238).

Es necesario enfatizar que ambos periódicos dirigen su acción a públicos diversos. The Economist lo dirige a accionistas y posibles inversionistas, para quienes la información en torno a los beneficios no es necesariamente mala. Por su parte The Forward se orienta a las clases explotadas que buscan una 
mayor justicia social. Por ello resalta el vínculo entre sus privaciones básicas, la precariedad laboral, los horrores de la guerra y el beneficio económico del capital.

El artículo desarrolla muchos más ejemplos, pero es conveniente sintetizar, que estos se basan en tres propósitos fundamentales: en primer lugar aprovechando la facticidad de la información contable se abre una nueva interpretación que socava la estabilidad de la información hegemónica; en segundo se demuestra la manipulación en la presentación de los informes y se restablece la facticidad para generar interpretación y por último se muestra el ocultamiento de hechos detrás de lo que se muestra, con la consecuente discusión acerca de las posibilidades de representación de la contabilidad.

En síntesis, los autores se alejan de pretensiones realistas de la contabilidad, y destacan su carácter discursivo. Afirman que el "significado no depende de cómo son las cosas, sino en la forma en que se significan, así que eventos similares pueden ser significadas de diferentes maneras" (Gallofer \& Haslam, 2006, p. 248).

De esta forma la actitud retórica contable, deriva de el hecho de resignificar eventos normalmente interpretados de una forma típica, para comenzar a tener una signficación desde la oposición. De allí emana la "política de la significación" (Gallofer \& Haslam, 2006, p. 248).

Los periodistas de Forward tuvieron una posición más cercana al código de oposición al leer inicialmente The Economist. Es decir, las cifras contables fueron leídas como una indicación de un enorme aumento de la ganancia en el contexto de aumento de los precios y se asocia con el sufrimiento de la gente. Esta lectura fue entonces muy influyente para la movilización de la contabilidad en defensa de las posturas contrahegemónicas.

Este texto directamente usa el concepto de retórica en un sentido emancipatorio, liberando con ello el concepto de la pertenencia exclusiva a las fuerzas hegemónicas. Además, reivindica el vínculo entre hermenéutica y retórica al establecer que una ade- cuada argumentación permite sustentar cierto tipo de interpretación. De esta forma en esa visión amplia de lo que implica la interpretación se acepta la posibilidad de que esos hechos representados mediante cuentas, sean juzgados a la luz de diversos marcos de referencia y con la capacidad de sustentar y materializar el proceso mediante el cual se llegan a esas conclusiones. En este caso la tendencia a establecer relaciones de concomitancia, cuando no de causalidad, entre las cuentas y los fenómenos de escasez y alto costo de vida, se convierten en factores lógicos que enmarcan la interpretación. Es el aspecto de facticidad que tanto se pregona dentro del artículo. Pero sobre todo, la capacidad de hacer ver, propia de la retórica, evidenciada en el lenguaje, mediante la alusión a casos concretos, el uso de metáforas o de expresiones extractadas del mundo de las invasiones bárbaras, apelaciones, preguntas retóricas, o ironía. En ese sentido tienen gran capacidad de penetración.

Finalmente, el contexto en el cual se enmarca el análisis, reitera la afirmación de Berinstain (1995), Beuchot (1998) y Meyer (1993), de que en tiempos hegemónicos, la retórica cumple fines de propaganda, en tanto en tiempos de convulsión y crisis, cumple funciones deliberativas muy fuertes.

\subsubsection{La emoción como fundamento de lo moral}

A pesar de no aludir a la retórica, el trabajo de McPhail (2004) ofrece elementos vinculantes con la retórica en lo relacionado con la visión de lo preferible como fundamento para la toma de decisiones. En el planteamiento del problema de investigación el autor plantea la reciente reivindicación de la emoción en el campo de la investigación contable, en ese sentido amplía las preocupaciones al campo de las decisiones de negocios, en las cuales las emociones se perciben como una distorsión para el tomador de decisiones. El autor, por el contrario, ve la emoción como fundamental en la toma de decisiones racionales. El autor sugiere que "una inteligencia emocional desarrollada es crucial para participar críticamente con el mundo" (McPhail, 2004, p. 630). 
El texto explora tres formas de relación entre razón y emoción: la primera es aquella que las interpreta como antitéticas, la segunda como complementarias y la tercera la cual expresa la razón como una forma de experimentar la emoción.

La postura antitética parte de Max Weber citado por McPhail (2004, p. 632), quien "sugiere que las emociones son espontáneas y las fuerzas impulsivas que distraen a una persona de sus propósitos. La implicación es que la emoción va a crear desorden en los asuntos humanos, mientras que la racionalidad permitirá poner en orden la conducta de un individuo". Weber ve como positiva la desaparición de la emoción en los sistemas burocráticos y concibe este hecho como la base para el desarrollo económico. Para McPhail (2004, p. 632) no es sorprendente tal postura, pero sí lo es la de Rousseau, quien afirmaba que "el paso del estado de naturaleza a los derechos civiles de la sociedad produce un cambio muy notable en el hombre... se ve obligado a consultar a su razón antes de escuchar sus inclinaciones" o en Habermas quien pugna por el rescate de la racionalidad en una sociedad posmoderna irracional. Igual desconocimiento se evidencia en las posturas críticas de la contabilidad. Dicha dicotomía ha sido impugnada dentro de los estudios organizacionales y el autor pretende hacerlo también desde la contabilidad.

Los avances embrionarios sobre el tema se detienen inicialmente en la autoconciencia emocional, la cual se refiere a la capacidad de leer nuestras emociones y las ajenas, y utilizar esta información en la toma de decisiones. De esta conciencia se deriva el concepto de inteligencia o competencia emocional, la cual se fundamenta en los aportes de Cohen (1999, citado por McPhail, 2004, p. 636), quien la define como la capacidad "de reconocer sus propios sentimientos y apreciar los sentimientos de los demás”, y los de Ana Freud, quien aseguraba que existe una especie de gramática emocional que permite el reconocimiento de las propias experiencias y las de los demás, como un bloque básico de la competencia social, de esta forma "La inteligencia social y emocional ofrece las bases para la regulación de la vida social, la esfera emocionales de la vida de los individuos, y la solución de problemas sociales y emocionales" (Cohen, 1999, citado por McPhail, 2004, p. 636).

No obstante, muchas de estas concepciones de la inteligencia emocional enfatizan en la empatía, la adaptación social y el manejo estratégico de las emociones, dejando de lado su potencial crítico.

Sin embargo "McIntosh \& Style (1999) comienzan a abordar este potencial cuando sugieren que un elemento clave en el Self es la exploración de las relaciones de poder que influyen en la forma en que estas competencias surgen y operan dentro de diferentes sistemas sociales y contextos económicos” (McPhail, 2004, p. 637). En síntesis, implica la exploración de la naturaleza política de las emociones.

Este autor no explora a fondo esta cuestión, pero si enfatiza la necesidad de desarrollar las competencias emocionales, para lo cual es necesario ubicar el desarrollo emocional dentro de una estructura evolutiva. Propone las siguientes etapas:

- Conciencia emocional: identificación de la emoción particular que uno siente y capacidad de nombrar la emoción que el otro siente.

- Adaptación sociocultural: capacidad de identificar las emociones apropiadas para situaciones específicas. Se asocia a las famosas competencias emocionales dentro del campo laboral y su relación con las virtudes propias de los profesionales(cortesía en el contador).

- Empatía emocional: capacidad para entrar en los sentimientos de otros. Va más allá de la identificación, implica la selección de respuestas adecuadas.

- La emotividad: una conciencia de las propias emociones que se utiliza conscientemente para guiar las acciones, está es concomitante a otros dominios de la inteligencia.

Describe una experiencia didáctica dentro del curso de ética; esta parte de la base de que el desarrollo emocional está relacionado con la capacidad 
de un individuo para aprender de sus experiencias emocionales y sociales (Cohen, 1999, citado por McPhail, 2004, p. 639).

El docente trabaja con tres casos. Dos narrados por las víctimas y otro vivido directamente por los estudiantes al permitirseles ubicarse en el punto de vista de quienes delinquen. El primero es la narración de una madre cuyo hijo nació con malformaciones como producto del consumo de Tylenol, el segundo es el caso de una mujer que consiguió reivindicaciones económicas para las víctimas de un sonado caso de fondo de pensiones en Inglaterra, cuya lucha permitió además lograr transformaciones regulatorias en el campo. Ambos casos les permitieron ubicarse en el sentimiento de las personas, superando con ello la tendencia a objetivar este tipo de situaciones. De esta forma hay un grado alto de empatía que les permite acercarse a la situación.

El tercer caso, les condujo a una prisión altamente hacinada en Glasgow, en ella pudieron visualizar las consecuencias que implica el delito y el fraude. Ubicarse en el escenario posible de la conducta ilegal les sirvió de advertencia, pero igualmente les permitió observar como detrás de muchas de las conductas delictivas se encuentra una base fundamental: la cosificación del ser humano, cosificación que pudieron vincular reflexivamente con la contabilidad como racionalidad del capital. Además, el hecho de que los testimonios se inserten en las narrativas de los implicados, les permitió desarrollar esa capacidad imaginativa que es la base para el desarrollo emocional.

Este texto implica un avance frente a las concepciones retóricas expresadas en la discusión de Green Peace, acá las emociones no se conciben como un acuerdo cultural que se mantiene y se aprovecha en beneficio de la propia causa. Tal afirmación se basa en la nueva retórica, en la cual Perelman (1997) insiste que las emociones no son beneficio de quien habla, sino que son el material que reconocemos en el otro para sacar avante nuestra posición. Esta postura de las emociones se centra más en la retórica de De Souza (2000), la cual no solo pugna por dotar de mayor racionalidad los topoi, sino que además rescata el afecto, la intución, el gusto y las emociones como base para una discusión social.
En este punto se destaca el concepto de verosimilitud como aquello que en contextos de incertidumbre se acerca a la verdad. Una verosimilitud que integra racionalidad y sentido de lo útil, lo bueno, lo bello y lo adecuado. Expresiones afectivas de base cultural que reclaman un replanteamiento de las mismas, en tanto cuestionen visiones cristalizadas del bien, de lo justo y lo correcto y obliguen a alejarse del supremo valor de la cantidad propio de la opinión pública. Desde este punto de vista, la narrativa de lo singular, que destaca lo único y lo precario, se convierte en un contrapeso vital para efectuar un contraste con lo establecido y lo que lógicamente se ha constituido y encerrado en el estrecho margen de la conceptualización.

Tal es el valor de las narrativas que se expresan en la experiencia didáctica de McPhail (2004), la mimesis de Ricoeur (1970) que permite reconfigurar el mundo del sujeto a partir del reconocimiento de la vivencia única del personaje, deriva en el valor imaginativo de la emotividad. La posibilidad de ubicarse en el otro, de construir el sentimiento del otro, nos acerca a las dimensiones sociales de las decisiones. Cuestiona la racionalidad abstracta y nos introduce a otro modo de racionalidad artistotélica, que integra logos, ethos y pathos, que reconoce las pasiones como base cultural de la virtud. Tal y como lo expresa Nussbaum (1996) al indicar que las diferencias culturales y conceptuales acerca de las esferas de la acción humana coinciden en ciertas preocupaciones fundamentales de la condición humana. Entre las cuales resalta dos fundamentales: la afiliación y la razón práctica. A partir de esta consideración es posible reconocer que el ser humano como ser social, tiene en el lenguaje la posibilidad de expresar sus dilemas y convicciones frente al mundo y que a partir del uso que de él haga podrá orientarse hacia fines instrumentales, impositivos o deliberativos. En esa disposición el concepto de virtud le permite acercarse a la diferencia y singularidad de lo humano:

Solo cuando hemos respondido con propiedad a las complejidades del contexto, y lo vemos como la situación histórica que es, podemos tener alguna esperanza de tomar la decisión correcta. Si no es 
asi, el uso de valores generales plausibles, sin importar lo bien intencionados que sean, no servirá de nada y podría empeorar las cosas. El aristotélico también argumenta que no hemos respondido sucificientemente al contexto que tenemos ante nosostros si no vemos lo humano en él: esto es, no respondemos a las demanadas de la necesidad humana, a los esfuerzos por alcanzar el bien, a las frustraciones de la capacidad humana, que esta situación presenta a la persona que reflexiona (Nussbaum, 1996, p. 337).

Así el valor de lo único en lo diverso descansa en el valor de lo humano. La búsqueda de la activa participación social no se basa en la satisfacción de fines inmediatos y utilitarios, ni en la imposición de verdades objetivas irrebatibles. La formación del juicio acepta que:

\section{(...) no es lo mismo construir formas de convivencia utlizando la persuasión cómo instrumento para lograr la adhe- sión a determinadas concepciones que buscan instaurar el poder de quienes tie- nen la palabra; que ser persuadidos con el fin de apostarle a la vida misma, a su conservación y a su bienestar, no sólo de cada uno sino de los seres humanos en general; como lo dice bien Ricoeur al hablar de Aristóteles: una retórica vigi- lada por la filosofía (Vargas \& Cárdenas, 2005, p. 23).}

\section{Conclusiones}

El vínculo entre retórica y contabilidad demuestra ser un campo lleno de posibilidades investigativas y formativas. Desde el punto de vista de la crítica retórica, las investigaciones desarrolladas ofrecen perspectivas metodológicas y conceptuales que contribuyen al desarrollo del análisis crítico del discurso contable. De igual forma, la aceptación del carácter interpretativo de la contabilidad en virtud no solo de su raíz social, sino de las evidencias empíricas que demuestran la presencia de intereses y valores como condicionantes del proceso de revelación contable; cuestiona la ilusión de neutralidad y abre para la contabilidad posibilidades de comprenderse como un producto y productor de interacciones sociales.

Para efectos emancipadores, la crítica retórica permite efectuar una discusión que devele los ocultamientos, tergiversaciones y manipulaciones propias del discurso hegemónico. No obstante, la crítica retórica deja entrever un supuesto que limita los alcances de la retórica: el pretender que es un instrumento estrictamente discursivo cuyo único propósito es mantener el status quo por lo que está al servicio del poder.

Una redefinición de la retórica, más allá de un enfoque discursivo, permite pensar que por ser consustancial a la vida social, la retórica deliberativa versa acerca de los juicios sobre la realidad, consecuentemente pretende determinar lo justo, bello, adecuado y correcto de acuerdo con ciertas circunstancias. En ese sentido se piensa más allá de un discurso adaptado al auditorio con el fin de garantizar la persuasión.

Una retórica deliberativa orientada a la defensa de lo público, exige el cuestionamiento de los lugares comunes en los cuales se afinca la contabilidad. Demanda además el reconocimiento del lenguaje como una forma de visibilizar las realidades que permanecen ocultas por el oscurecimiento de la contabilidad convencional; ello implica ampliar los posibles auditorios que sirvan como medio de presión en asuntos sociales, así como ampliar las posibilidades del lenguaje contable para que dé cuenta de realidades diversas y llegue a ese público al cual se pretende movilizar. Requiere una contabilidad que provea argumentos lógicos mediados por una interpretación argumentada, pero igualmente demanda la aceptación de las pasiones como elemento fundante del juicio, pues gracias a estas se puede mover a la acción. No obstante estas pasiones no operan solo sobre el auditorio, sino que debe ser un criterio que acompañe la toma de decisiones en tanto la propia conciencia de lo bello, lo bueno y lo justo, son el fundamento de lo preferible para emprender discusiones sociales que se alejan de pretensiones estratégicas y se orienten hacia el bien común. 
Los escasos ejemplos presentados, demuestran que la retórica también puede estar al servicio de la deliberación contable. Por una parte la aceptación de que toda investigación contable es retórica implica que se hace desde valores y convoca a pensar el modelo de sociedad que se asume al investigar, algo que Gómez (2003) ha planteado como los determinantes morales de la investigación contable. De igual forma, el caso de la disputa entre Greenpeace,y las empresas de ropa deportiva, confirma que las estrategias retóricas pueden estar al servicio de la presión pública. Gracias a estrategias discursivas de diversa índole, amparados en una convicción ambiental y apuntando a diversos grupos de presión, se demuestra que la retórica no solo está al servicio del poder, sino que puede apoyar las luchas de los grupos contrahegemónicos. Sobre todo en un entorno como el actual, en el cual las comunicaciones se han expandido y han permitido que ideas emergentes sean visibles y movilicen el activismo político. Algo similar se puede deducir de la experiencia del periódico Forward, la cual reitera que la contabilidad va más allá de las cifras, que estas no hablan por sí solas, y que en asuntos de revelación, la forma como se presente la información contable, y la manera como se interprete, es fundamental para definir acciones futuras y evaluar las pasadas.

Son simples trazos que apuntan a reivindicar el ejercicio retórico. Expresan el deseo por una ciencia reconstituida para aceptar sus propios límites y decidida a tomar la responsabilidad que se requiere para persuadir y para dejarse persuadir (Scott, 1976, citado por Restrepo, 2004). "Una ciencia que acepta sus propias incertidumbres, su propio carácter discursivo, que no niega sus estrategias de persuasión; unos expertos que están dispuestos no sólo a discutir los hechos sino también los valores y los intereses que informan la producción de esos hechos. Esta sería una ciencia sin retórica entre comillas, más exactamente una ciencia sin anti-retórica. Para que la discusión fluya, como debe fluir" (Restrepo, 2004, p. 265).

\section{Referencias}

Addison, S. \& Mueller, F. (2015). The dark side of professions: the big four and tax avoidance. Accounting, Auditing and Accountability Journal, 25(8), 1263-1290.

Agyemang, G. \& Lehman, C. (2013). Adding critical accounting voices to migration studies. Critical Perspectives on Accounting, 24, 261-272.

Aho, J. (2005). Confession and bookkeeping: The religious, moral, and rhetorical roots of modern accounting. New York: State University of New York Press.

Ahrens, T. (1996). Styles of accountability. Accounting, Orgnnizatfons and Societ, 21(2/3), 139-176.

Amernic, J. \& Craig, R. (2001). Three tenors in perfect harmony: "Close readings" of the joint letter by the heads of aluminium giants Alcan, Pechiney, and Alusuisse announcing their mega-merger plan. Critical Perspectives on Accounting, 12(6), 763-785.

Arendt, A. (2009). La Condición humana (1 ed.). (R. Gil Novales, Trad.) Buenos Aires: Paidós.

Arrington, E. \& Schweiker, W. (1992). The rhetoric and rationality of accounting research. Accounting Organizations andSocieCy, 17(6), 511-533.

Baker, C. (2005). What is the meaning of "the public interest"?: Examining the ideology of the American public accounting profession. Accounting, Auditing and Accountability Journal, 18(5), 690-703.

Baldvinsdottir, G., Burns, J., Nørreklit, H. \& Scapens, R. (2009). The image of accountants: From bean counters to extreme accountants. Accounting, Auditing and Accountability Journal, 22(6), 858-882.

Bourguignon, A. (2005). Management accounting and value creation: The profit and loss of reification. Critical Perspectives on Accounting, 16(4), 353-389.

Brennan, N., Daly, C. \& Harrington, C. (2010). Rhetoric, argument and impression management in hostile takeover defence documents. British Accounting Review, 42(4), 253-268.

Bujaki, M. (2010). Cost-benefit analysis in correspondence related to building the Rideau Canal. Accounting History, 15(2), 229-251.

Burke, R. \& Demirag, I. (2015). Changing perceptions on PPP games: Demand risk in Irish roads. Critical Perspectives on Accounting, 27, 189-208.

Carmona, S. \& Gutiérrez, F. (2005). Outsourcing as compassion? The case of cigarette manufacturing by poor Catholic nuns (1817-1819). Critical Perspectives on Accounting, 16(7), 875-903.

Carter, C. \& Cooper, S. (2006). The poetics of corporate reporting: Evidence from the UK water industry. Critical Perspectives on Accounting, 17, 175-201.

Collier, P. (2006). Costing police services: The politicization of accounting. Critical Perspectives on Accounting, 17, 57-86

Courtis, J. (2004). Colour as visual rhetoric in financial reporting. Accounting Forum, 28(3), 265-281. 
Covaleski, M., Dirsmith., M. \& Rittenberg, L. (2003). Jurisdictional disputes over professional work: The institutionalization of the global knowledge expert. Accounting, Organizations and Society, 28(4), 323-355.

Craig, R. \& Amernic, J. (2004). Enron discourse: The rhetoric of a resilient capitalism. Critical Perspectives on Accounting, $15,813-851$.

Craig, R. \& Amernic, J. (2006). The mobilization of accounting in preening for privatization. Accounting, Auditing and Accountability Journal, 19(1), 82-95.

Craig, R. \& Armenic, J. (2008). A privatization success story: Accounting and narrative expression over time. Accounting, Auditing and Accountability Journal, 21(8), 1085-1115.

Davidson, J. (2008). Rhetoric, repetition, reporting and the "dot. com" era: Words, pictures, intangibles. Accounting, Auditing and Accountability Journal, 21(6), 791-826.

Davidson, J. (2010). [In]visible [in]tangibles: Visual portraits of the business élite. Accounting, Organizations and Society, 35(2), 165-183.

Davidson, J. (2014). Visual rhetoric and the case of intellectual capital. Accounting, Organizations and Society, 12(6), 763-795.

Davidson, J. (2015). Visualising accounting: An interdisciplinary review and synthesis. Accounting and Business Research, 45(2), 121-165.

De Souza, B. (2000). Crítica de la razón indolente: contra el desperdicio de la experiencia. Para un uevo sentido común: la ciencia, el derecho y la políitca en la nueva transición paradigmática.a . Sao Paulo: Desclee de Brouwer S.A. .

Deegan, C. (2012). Corporate Commitment to Sustainability-Is it All Hot Air? An Australian Review of the Linkage between Executive Pay and Sustainable Performance. Australian Accounting Review, 22(4), 384-397.

Dent, H. (2006). Delivering patient choice in English acute hospital trusts. Accounting Forum, 30(4), 359-376.

Ezzamel, M., Willmott, H. \& Worthington, F. (2004). Accounting and management-labour relations: The politics of production in the 'factory with a problem'. Accounting, Organizations and Society, 29, 269-302.

Free, S. (2009). The construction of auditability: MBA rankings and assurance in practice. Accounting, Organizations and Society, 34(1), 119-140.

Free, C. (2007). Supply-chain accounting practices in the UK retail sector: Enabling or coercing collaboration? Contemporary Accounting Research, 24(3), 897-933.

Froud, J. (2003). The Private Finance Initiative: Risk, uncertainty and the state. Accounting, Organizations and Society, 28(6), 567-589.

Galeano, M. (2004). Diseño de proyectos en la investigación cualitativa. Universidad Eafit, Medellín.

Gallofer, S. \& Haslam, J. (2006). Mobilising accounting in the radical media during the First World War and its aftermath: The case of Forward in the context of Red Clydeside. Critical Perspectives on Accounting, 17, 224-252.

Gómez, M. (2003). Contabilidad: comentarios sobre el discurso científico y los determinantes morales. Innovar, Revista de Ciencias administrativas y Sociales (22), 109-120.
Gómez, M. (2007). Pensamiento único y contabilidad: la posibilidad de la contabilidad como disciplina moral. (U. M. Granada, Ed.) Revista Facultad de Ciencias Económicas: Investigación y Reflexión, XV(2), 29-43.

Gómez, M. \& Ospina, C. (2009). Avances interdisciplinarios para una comprensión crítica de la contabilidad. Textos paradigamàticos de las corrientesw heterodoxas. (M. Gòmez, Trad.) Medellín: Universidad de Antioquia, Universidad Nacional de Colombia.

Gond, J-P., Grubnic, S., Herzig, C. \& Moon, J. (2012). Configuring management control systems: Theorizing the integration of strategy and sustainability. Management Accounting Research, 23(3), 205-223.

Higgins, C. \& Walker, R. (2012). Ethos, logos, pathos: Strategies of persuasion in social/environmental. Accounting Forum, $36,194-208$

Holloway, D. (2004). Strategic planning and Habermasian informed discourse: Reality or rhetoric. Critical Perspectives on Accounting, 15, 469-483.

Hooper, K. \& Kearins., K. (1995). The rise and fall of the Judge and Renouf Corporations: Extravagant reporting and publicity. Accounting, Business \& Financial History, 5(2), 187-210.

Hrasky, S. (2012). Auditing and crisis management: The 2010 Melbourne Storm salary cap scandal. Accounting, Organizations and Society, 37(3), 131-154.

Ihantola, E-M. (2010). An historical analysis of budgetary thought in Finnish specialist business journals from c. 1950 to c.2000. Accounting, Business and Financial History, 20(2), 135-161.

Irvine, H. (2012). A genealogy of calculations at an early Queensland sugar mill. Accounting History, 17(2), 193-219.

Jiménez, R. (2012). Contabilidad: entre la responsabilidad social y el interés público. Criterio Libre, 10(17), 219-234.

Laine, M. (2005). Meanings of the term 'sustainable development' in Finnish corporate disclosures. Accounting Forum, 29(4), 395-413.

Laine, M. (2010). Towards sustaining the status quo: Business talk of sustainability in finnish corporate disclosures 1987-2005. European Accounting Review, 19(2), 247-274.

Lawrence, S. \& Sharma, U. (2002). Commodification of education and academic labour-Using the balanced scorecard in a university setting. Critical Perspectives on Accounting, 13, 661-677.

Lehman, C. (2006). The bottom line. Critical Perspectives on Accounting, 17 (2-3), 305-22

Lehman, C. (2012). We've come a long way! Maybe! Re-imagining gender and accounting. Accounting, Auditing and Accountability Journal, 25(2), 256-294.

Lehman, C. \& Tinker, T. (1987). The "real" cultural significance of accounts. Accounting, Organizations and Society, 12(5), 503-522.

Mäkelä, H. \& Näsi, S. (2010). Social responsibilities of MNCs in downsizing operations: A Finnish forest sector case analysed from the stakeholder, social contract and legitimacy theory point of view. Accounting, Auditing and Accountability Journal, 23, 149-174.

Malmi, T. \& Ikäheimo, S. (2003). Value Based Management practices-Some evidence from the field. Management Accounting Research, 14(3), 235-254. 
Malmmose, M. (2015). Management accounting versus medical profession discourse: Hegemony in a public health care debateA case from Denmark. Critical Perspectives on Accounting, 27, 144-159.

Matilal, S. \& Höpfl, H. (2009). Accounting for the Bhopal disaster: Footnotes and photographs. Accounting, Auditing and Accountability Journal, 22(6), 353-372.

McPhail, K. (2004). An emotional response to the state of accounting. Critical Perspectives on Accounting(15), 629-648.

McSweeney, B. (1997). The unbearable Ambiguity of accounting. Accounting, Organizations and Society, 22(7), 691-712.

Merino, B. \& Mayper, A. (2001). Securities legislation and the accounting profession in the 1930s: The rhetoric and reality of the American dream. Critical Perspectives on Accounting, 12(4).

Miller, P. \& O'Leary, T. (1990). Making accountancy practical. Accounting, Organizations and Society, 21(4), 477-498.

Milne, M., Tregidga, H. \& Walton, S. (2009). Words not actions! The ideological role of sustainable development reporting. Accounting, Auditing and Accountability Journal, 22(8), 1211-1257.

Moerman, L. \& van der Laan, S. (2007). Pursuing shareholder value: The rhetoric of James Hardie. Accounting Forum, 31(4), 354-369.

Nelson, W. \& Hirsch, P. (1990). Ownership changes, accounting practice and the redefinition of the corporation. Accounting, Organizations and Society, 15(1), 77-96.

Niamh, B. \& Merckl Davis, D. (2014). Rhetoric and Argument in Social and Environmental Reporting:. Accounting, Auditing and Accountability Journal, 4, 602-639.

Nørreklit, H. (2003). The Balanced Scorecard: What is the score? A rhetorical analysis of the Balanced Scorecard. Accounting, Organizations and Society, 28, 591-619.

Nussbaum, M. (1996). Virtudes no relativas un enfoque aristotélico. En: M. Nussbaum \& A. Sen, La calidad de vida (pp. 318-351). México D.F.: Fondo de Cultura Económica.

Graves, O., Jordan, R. \& Fleshe, R. (1996). Pictures and the bottom line: The television epistemology of U.S. annual reports. Accounting, Organizations and Society, 21, 57-88.

O'Dwyer, B. (2010). Enhancing the role of accountability in promoting the rights of beneficiaries of development NGOs. Accounting and Business Research, 40(5), 451-471.

O'Dwyer, B. \& Unerman, J. (2007). From functional to social accountability: Transforming the accountability relationship between funders and non-governmental development organisations. Accounting, Auditing and Accountability Journal, 20(3), 446-471.

Perelman, C. (1997). El imperio retórico. Traducción Gómez. A.L. Bogotá, Colombia: Norma.

Perelman, C. \& Olbrechts Tyteca, L. (1989). Tratado de la argumentación. La nueva retórica. Traducción D. Alonso, Ed., \& J. Sevilla Muñoz. Madrid: Editorial Gredos.

Pesci, C., Costa, E. \& Soobaroyen, T. (2015). The forms of repetition in social and environmental reports: Insights from
Hume's notion of 'impressions'. Accounting and Business Research, 45, 765-800.

Pesci, C., Costa, E. \& Soobaroyen, T. (2015). The forms of repetition in social and environmental reports: Insights from Hume's notion of 'impressions'. Accounting and Business Research, 45, 765-800.

Quinche, F. (2011). Perspectivas de investigación, retórica y contabilidad: una invitación. Lúmina, 12, 216-239.

Quinche, F. (2012). El potencial de los estudios retóricos en la investigación contable. Revista de la Facultad de Ciencias Económicas de la Universidad Militar Nueva Granada, XX (1), 247-268.

Quinche, F. (2014). Desresponsabilización mediante la 'responsabilidad social': una evaluación retórica a las 'cartas de los presidentes' presentes en tres informes de responsabilidad social empresarial en Colombia. Cuadernos de Contabilidad, 15(37), 153-185.

Restrepo, O. (2004). Retórica de la ciencia sin "retórica". Revista colombiana de sociología, 23, 251-268.

Ricoeur, P. (1970). Retórica, poética y hermenéutica. Efímero: Escombrera filosófica.

Ruiz, G. (2014). Hacia la comprensión de la retórica como contenido formativo para la configuración de un sujeto deliberativo. Tesis maestría en Educación. Facultad de Educación, Universidad de San Buenaventura seccional Medellín. Disponible en: http:// bibliotecadigital.usb.edu.co/bitstream/10819/2770/1/Comprension_Retorica_Formativo_Ruiz_2014.pdf

Sawabe, N. (2005). Accounting for the public interest: A Japanese perspective. Accounting, Auditing and Accountability Journal, 18(5), 631-647.

Seal, Y. (2014). The balanced scorecard and the construction of a management control discourse. Journal of Accounting and Organizational Change, 10(4), 466-485.

Sharma, U. \& Lawrence, S. (2015). Power, politics and privatization: A tale of a telecommunications company. Critical Perspectives on Accounting, 28, 13-29.

Silez Ruiz. J. (2012). La Retórica en la formación del ciudadano: tradición, vigencia y actualidad. Retórica y Política: los discursos de la construcción de la sociedad, Logroño: Instituto de Estudios Riojanos, 21-32.

Taylor, S. (2011). Captured Legislators and Their Twenty Billion Dollar Annual Superannuation Cost Legacy. Australian Accounting Review, 21(3), 266-281.

Thompson, G. (1991). Is accounting rhetorical? Methodology, Luca Pacioli and printing. Accounting, Organizations and Society, 16, 572-599.

Vargas, G. \& Cardenas, L. (2005). Retórica, poética y formación. ISBN: 9588226627 Ed. Universidad Pedagógica Nacional, Bogotá.

Yamey, B. (2005). The historical significance of double-entry bookkeeping: Some non-Sombartian claims. Accounting, Business and Financial History, 15(1), 77-88. 